\title{
HEMATITA VS. ARCILLAS: SU POTENCIAL COMO PIGMENTOS ROJOS Y SU USO EN TRES SITIOS DE LA PUNA JUJEÑA (ARGENTINA)
}

\section{HEMATITE VS. CLAYS: THEIR POTENTIAL AS RED PIGMENTS AND THEIR USE IN THREE SITES AT THE PUNA OF JUUUY (ARGENTINA)}

\author{
Patricia Solá*, Hugo D. Yacobaccio* *, \\ Mariana RosenbusCH ${ }^{*} *$ * María Susana \\ AlONSO****, MARTA S. MAIER $* * * *$, \\ CRISTINA VÁZQUEZ $* * * * * * \&$ \\ MARÍA PAZ CATÁ*******
}

El análisis de pinturas rojas en pictografías de tres sitios de la Puna jujeña puso de manifiesto el uso exclusivo de hematita en su realización. Este pigmento rojo fue utilizado en la región desde inicios de la ocupación humana y su reiterada presencia en representaciones pictóricas diacrónicas revela la especificidad de esa materia prima en Hornillos 2, Cueva Quispe y Tres Pozos. Los pigmentos rojizos recuperados de los niveles estratigráficos en dos de los sitios están constituidos por hematita y por arcillas rojas. El uso de uno u otro tipo de pigmento estaría relacionado con las propiedades intrínsecas de ambas especies minerales, por tal motivo, planteamos que fueron utilizadas con fines diferentes.

Palabras clave: pinturas rupestres, hematita, arcillas rojas, usos, Puna jujeña

Physical-chemical characterization of red paints from pictographs found at three sites in the Puna of Jujuy shows that hematite was the only pigment used in their execution. Hematite pigment was used in the region from the earliest human occupations and its recurring presence in diachronic rock paintings reveals the specificity of this material in Hornillos 2, Cueva Ouispe and Tres Pozos. In addition to bematite, reddish pigments recovered from stratigraphic levels include clay pigments. As the use of one kind of pigment over another would be linked to its intrinsic properties, we propose that these different pigments were used for different purposes.

Key words: rock paintings, hematite, red clays, uses, Puna of Jujuy

\section{INTRODUCCIÓN}

El objetivo de esta investigación ha sido establecer qué usos tuvieron los distintos tipos de pigmentos -los óxidos férricos y las arcillas (rojas) - y cómo se fue diversificando su aplicación desde los tiempos de los primeros cazadores-recolectores hasta los momentos más tardíos de la prehistoria regional.

La caracterización fisicoquímica de las pinturas rojas de tres sitios con pictografías de la región de Susques (Puna jujeña) permitió establecer correspondencias entre los componentes pigmentantes utilizados. En efecto, las pinturas rupestres del alero Hornillos 2 (Hor2), Cueva Quispe (CQ) y Tres Pozos (TP) (fig. 1) muestran similitud en cuanto a la materia prima pigmentante y a las técnicas de preparación de las pinturas -molido y mezcla de componentes de variados orígenes-, aunque se detectaron ciertas diferencias en los materiales empleados como carga y ligante de los pigmentos; asimismo, son diferentes los motivos representados y los estilos pictóricos, al igual que el registro arqueológico, la cronología de las ocupaciones, la temática y la magnitud y el tipo de representaciones.

* Patricia Solá, Conicet-Instituto de Arqueología (IDA-FFyL, UBA). 25 de Mayo 221, $3^{\circ}$ Piso (C1002ABE) Ciudad Autónoma de Buenos Aires Argentina, email: patriciasola@gmail.com

* Hugo D. Yacobaccio, ConicET-IDA (FFyL, UBA), Argentina, email: hdyacobaccio@gmail.com

* Mariana Rosenbusch, Centro Atómico Constituyentes, CNEA-ConiceT. Prov. de Buenos Aires, Argentina, email: rosenbus@cnea.gov.ar

**** María Susana Alonso, IGeBA (ConicET-UBA) y Departamento de Ciencias Geológicas (FCEyN, UBA), Argentina, email: sualonso@gl.fcen.uba.ar

***:**: Marta S. Maier, UMYMFOR-Departamento de Química Orgánica (FCEYN, UBA), Argentina, email: maier@qo.fcen.uba.ar

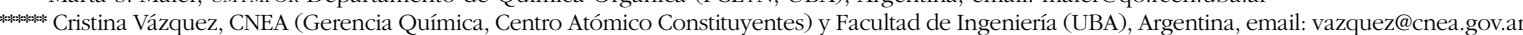

**:**:**aría Paz Catá, IDA (FFyL, UBA), Argentina, email: mariapazcata@gmail.com 
El alero Hor2 sirvió de reparo a grupos de cazadoresrecolectores desde el límite Pleistoceno / Holoceno temprano hasta el Holoceno medio (11.650-6990 cal AP) (Hoguin et al. 2012; Yacobaccio et al. 2013). En cambio, CQ fue ocupada en el lapso entre $764 \mathrm{cal} \mathrm{AC}$ y 1030 cal DC) (Yacobaccio et al. 1997-1998, 2011) y TP, ocupado por pastores, ha sido asignado a una cronología similar por la tecnología lítica asociada y el estilo de las representaciones rupestres.

Las investigaciones anteriores permitieron establecer que en Hor2 y CQ las pinturas rojas (desde ocres a variadas tonalidades de rojos) sobre pared estaban compuestas por un solo tipo de pigmento -el óxido férrico hematita-, a pesar de que en capa también se encontraron fragmentos rojizos de base arcillosa (Yacobaccio et al. 2008, 2011, 2012). En función de las cronologías, se infiere que una parte de los componentes arcillosos de capa de CQ pudo ser usada en la manufactura de vasijas de barro, por ejemplo, en los tratamientos superficiales -engobes- y decoraciones pintadas (Yacobaccio et al. 2011). En Hor2, en cambio, los pigmentos de base arcillosa recuperados en capa debieron ser utilizados en actividades no relacionadas con la alfarería, ya que el sitio estuvo activo hasta el Holoceno medio, categóricamente precerámico. Entonces, cabe preguntarse: ¿por qué la matriz sedimento-antropogénica de Hor 2 contenía relictos pigmentantes arcillosos si estos no fueron utilizados en las representaciones pictóricas y en qué otras actividades pudieron ser empleados, puesto que fueron conservados al igual que los óxidos de hierro?

La recurrencia del uso de determinados minerales en las pinturas rojizas de este sector de la Puna jujeña permitió plantear que los óxidos férricos debieron ser seleccionados por ser pigmentos rojos muy estables y duraderos. En cambio, las arcillas (rojas) debieron ser empleadas en actividades que no requerían de la estabilidad fisicoquímica de los óxidos férricos. Se plantea que fueron las propiedades intrínsecas de ambos compuestos minerales las que prevalecieron durante la elección de una u otra materia prima según el tipo de actividad planificada.

En otras representaciones pictóricas de la Puna jujeña, también se han registrado óxidos de hierro, aunque en Inca Cueva (c4), el pigmento rojo/rojo violáceo utilizado fue plumbojarosita (sulfato de plomo y hierro), si bien algunos motivos fueron repintados con hematina (Aschero 1983-1985; Aschero \& Podestá 1986). La hematita es el pigmento de las pinturas rojas (tardías) del Alero de las Circunferencias (Hernández Llosas \& Podestá 1979-1982) y del Abrigo de los Emplumados (Hernández Llosas \& Podestá 1983-1985; Hernández Llosas et al. 1999). El resto de los sitios de la Puna jujeña con pictografías rojas carece de estudios fisicoquímicos o los datos son poco precisos, entre ellos, Cueva El Toro y Cueva de Cristóbal (Fernández 1976, 1988-1989), Cueva Redonda (Humahuaca) y Cueva Peña Aujero (Quebrada de Coraya) (Schobinger \& Gradin 1985) y numerosos sitios en las regiones del río Doncellas (p. e., Cueva del Hechicero), Rinconada, Casabindo, Coranzulí, Huachichocana y Barrancas (Fernández Distel 2001).

Asimismo, en el Noroeste Argentino, los pigmentos fueron utilizados para pintar cueros -mantas, mantos o quillangos, bolsitas, tabaqueras, calzados- y en rituales y enterratorios. Rosen (1957: 94-95) halló bolsas de cuero "[...] para guardar colores [...] seguramente usados para pintar o tatuar el cuerpo" en una sepultura tardía de Casabindo insinuando que el color rojo sería "óxido de hierro natural", pero no presenta estudios analíticos que lo sustenten. En la cuenca del río Doncellas, E. Casanova menciona cueros pintados y "sonajeros" pintados de rojo y hace referencia a un enterratorio en la Cueva del Hechicero de "[...] un individuo adulto con el cuerpo parcialmente cubierto por una máscara de cuero pintada de rojo" (Casanova 1967: 2); sin embargo, el cuero aludido, aunque pintado de rojo, no tiene forma de máscara. En Inca Cueva (c7), Aguerre y colaboradores (1973: 212-213, 215-216) hallaron bolsitas, vinchas, tientos de cuero e instrumentos musicales pintados de rojo y Aschero (1984) halló dos cueros de vicuña en Inca

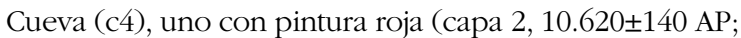
Aschero \& Podestá 1986). En este trabajo será analizada la pintura roja del cuero recuperado en la capa 2 de Inca Cueva (c4).

En sitios de la Patagonia con arte rupestre, también se determinaron pigmentos de oxihidróxidos de hierro: goethita, hematita y/o maghemita (Iñíguez \& Gradin 1977; Gradin 1978; Aschero 1983-1985; Barbosa \& Gradin 1986-1987; Wainwright et al. 2000, 2002; Boschin et al. 2002, 2011; Maier et al. 2007). Igualmente, ha sido atribuido el uso de arcillas en pinturas pleistocénico / holocénicas en sitios de Santa Cruz (Paunero et al. 2005: 161) y, en sitios de Tierra del Fuego (Fiore et al. 2008), se han registrado, en capa, residuos de pinturas preparadas, es decir, la "masa" generada a partir de la mezcla de pigmento, carga y ligante orgánico.

Del mismo modo, en otras regiones del país se estudiaron artículos y procesos que involucraron materiales pigmentantes, p. e., tecnofacturas de cuero, pieles y objetos pintados de rojo (plaquetas, hachas), la manera de preparar las pinturas y prácticas enterratorias, así como los factores sociales que impulsaron a aborígenes de Tierra del Fuego a incluir entre sus actividades habituales la pintura facial y corporal (Gómez Otero 1996-1997; 
Lagiglia 1997; Aguerre 2000; Caviglia 2003; Fiore 2004, 2006; Martínez et al. 2006; Boschin et al. 2011).

También el pigmento hematina fue utilizado frecuentemente como antiplástico y engobe en la alfarería prehispánica de las regiones Pampeana, Nordpatagónica y del Paraná inferior (Hajduk 1978; González de Bonaveri et al. 2000; Pérez 2009; Matarrese et al. 2011, entre otros).

\section{UBICACIÓN Y AMBIENTE LOCAL}

La región de Susques se localiza en la Puna jujeña occidental, en la zona de transición entre la Puna Seca y la Salada, entre los 3600 y 4500 msnm (fig. 1). El relieve es un altiplano formado por lomas y serranías con valles del tipo de bolsones alargados y poco profundos; la zona cuenta con un sistema hidrológico con cursos de agua permanentes -río Pastos Chicos, de las Burras, Coranzulí- y estacionales (la mayoría de las quebradas de rumbo oeste-este) que desaguan en la cuenca (endorreica) laguna de Guayatayoc-Salinas Grandes. La región se caracteriza por el clima frío y seco, la gran amplitud térmica diaria y la alta evaporación. Las lluvias se concentran en los meses estivales con medias anuales inferiores a $200 \mathrm{~mm} / \mathrm{a}$.

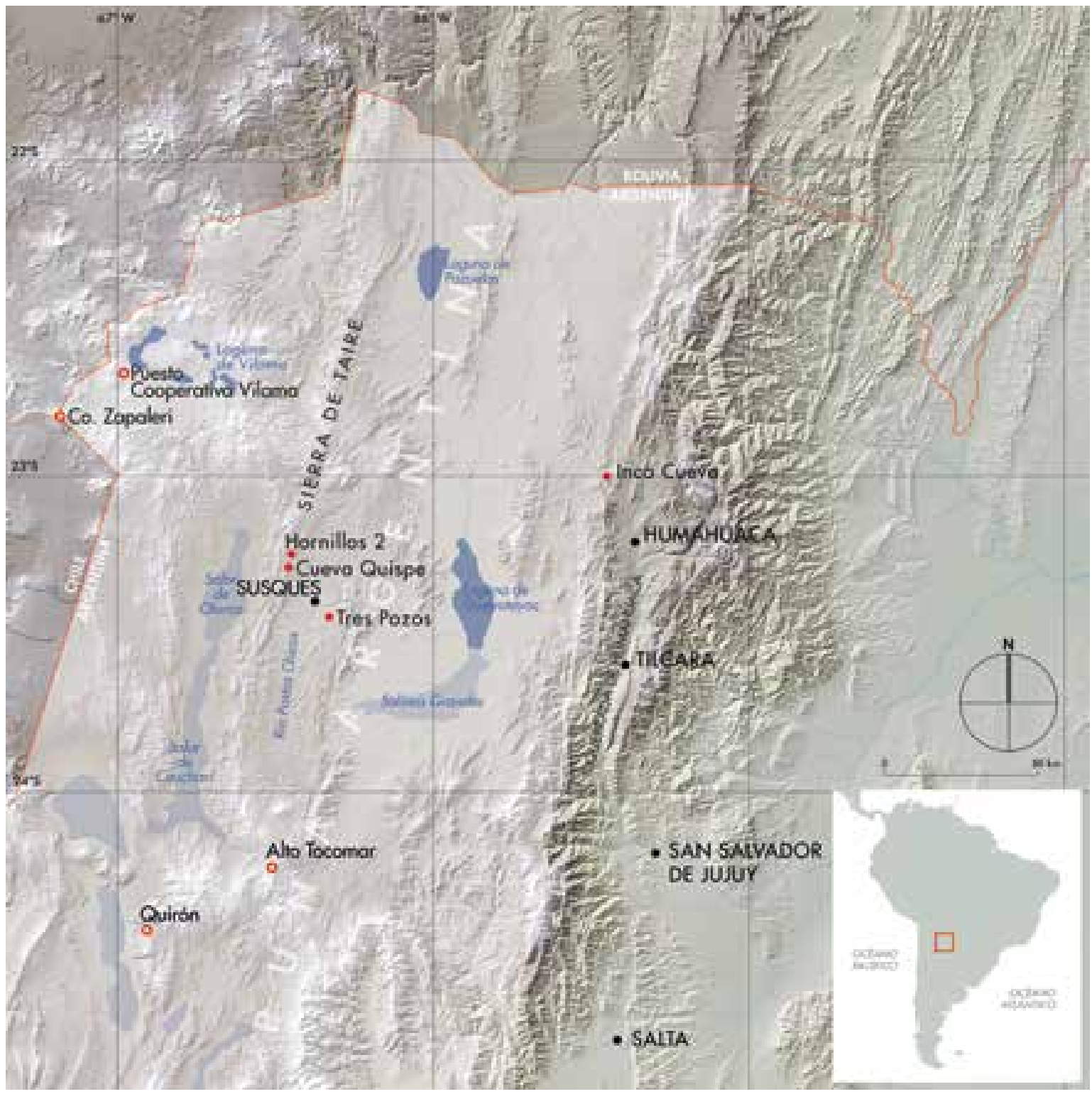

Figura 1. Ubicación geográfica de los sitios con pictografías rojas discutidos en el texto.

Figure 1. Geographic location of sites with red pictographs discussed in the text. 


\section{LAS PINTURAS ROJAS DE LOS SITIOS DE SUSQUES}

En la región de Susques hay numerosos sitios arqueológicos (Yacobaccio et al. 1997-1998), pero solo se han registrado manifestaciones pictóricas en Hor2, CQ y TP.

Hornillos 2 (2313'47”s, 66²7'22”O; 4020 msnm) es una pequeña cueva asociada con un alero rocoso que se ubica a $20 \mathrm{~km}$ al NNO del pueblo de Susques (fig. 1). Este alero, con un ancho de $20 \mathrm{~m}$ y una profundidad máxima de $5 \mathrm{~m}$, está emplazado en la base de un farallón ignimbrítico, sobre la ladera oriental de la Serranía del Taire. Los restos arqueológicos -estructuras de combustión, artefactos y desechos líticos, restos óseos de camélidos, cérvidos y chinchíllidos, pigmentos y el arte rupestre y mobiliar- evidencian la práctica de actividades domésticas en el sitio (Hoguin et al. 2012; Yacobaccio et al. 2013). La pared de fondo del alero contiene un panel con motivos pintados en cuatro colores; se trata de 28 figuras de camélidos, cinco antropomorfos y un ave (fig. 2). Las pinturas también contenían yeso (carga) y abundante materia orgánica de origen animal (ligante) (Vázquez et al. 2008; Yacobaccio et al. 2008, 2012). De excavación se obtuvieron 64 fragmentos pigmentantes de colores ocres a rojos oscuros ( $\mathrm{N}_{\text {ANALIZADO: }}$ ).

Cueva Quispe (2316’25”S, 66²7’39”O; $4091 \mathrm{msnm}$ ) es una amplia cueva de $14,5 \mathrm{~m}$ de ancho y $8 \mathrm{~m}$ de profundidad máxima; está emplazada a unos $50 \mathrm{~m}$ por encima del nivel de base de la ignimbrita local. Se ubica a pocos kilómetros al sur de Hor 2 y a unos 17 km al
NNO de Susques (fig. 1). El análisis de arqueofauna, material lítico, cerámica y cordelería permitió establecer el uso temporario de la cueva por pastores que realizaban actividades de caza (Yacobaccio et al. 2011). Hay una sola figura pintada en color ocre (7,5 YR 6/6 Reddish yellow) y, en capa, se hallaron 69 fragmentos pigmentantes ( $\mathrm{N}_{\mathrm{ANALIZADO}}$ : 12 ). La figura pintada representa una llama de perfil con las orejas paradas, la cola inclinada hacia adelante y el "faldón" que caracteriza a los camélidos domesticados (largo del cuerpo: $17 \mathrm{~cm}$, altura oreja/pata: $19,5 \mathrm{~cm}$ ) (fig. 3).

Tres Pozos (2326’33,1"S y 66²18'13,6”O; a 3786 msnm) es un sitio a cielo abierto, sin estratigrafía asociada, ubicado a $12 \mathrm{~km}$ al SE de Susques (fig. 1). Está asentado al pie de la formación ignimbrítica que, en este sector, presenta una escarpa de frente recto de unos $15 \mathrm{~m}$ de altura; los pastores actuales utilizan el lugar como corral y revolcadero de animales. De la ocupación antigua se conservan las manifestaciones rupestres y el material lítico y cerámico esparcido sobre la superficie aterrazada que buza hacia el oriente. ${ }^{1}$ Las representaciones rupestres - pinturas rojas y grabados- de este sitio se ubican a diferentes alturas respecto del nivel del piso (hasta $2,20 \mathrm{~m}$ ) y se extienden a lo largo de $17 \mathrm{~m}$. Destacan tres sectores: a) sector 1 , un panel con camélidos grabados (llamas); b) sector 2, un panel de 1,60 m de ancho con camélidos grabados, las figuras grandes tienen hasta $34 \mathrm{~cm}$ de largo y/o alto y las figuras chicas tienen un alto de 8 a $12 \mathrm{~cm}$; c) sector 3, un panel pintado de 2,60 m de ancho con figuras antropomórficas rojas (fig. 4).

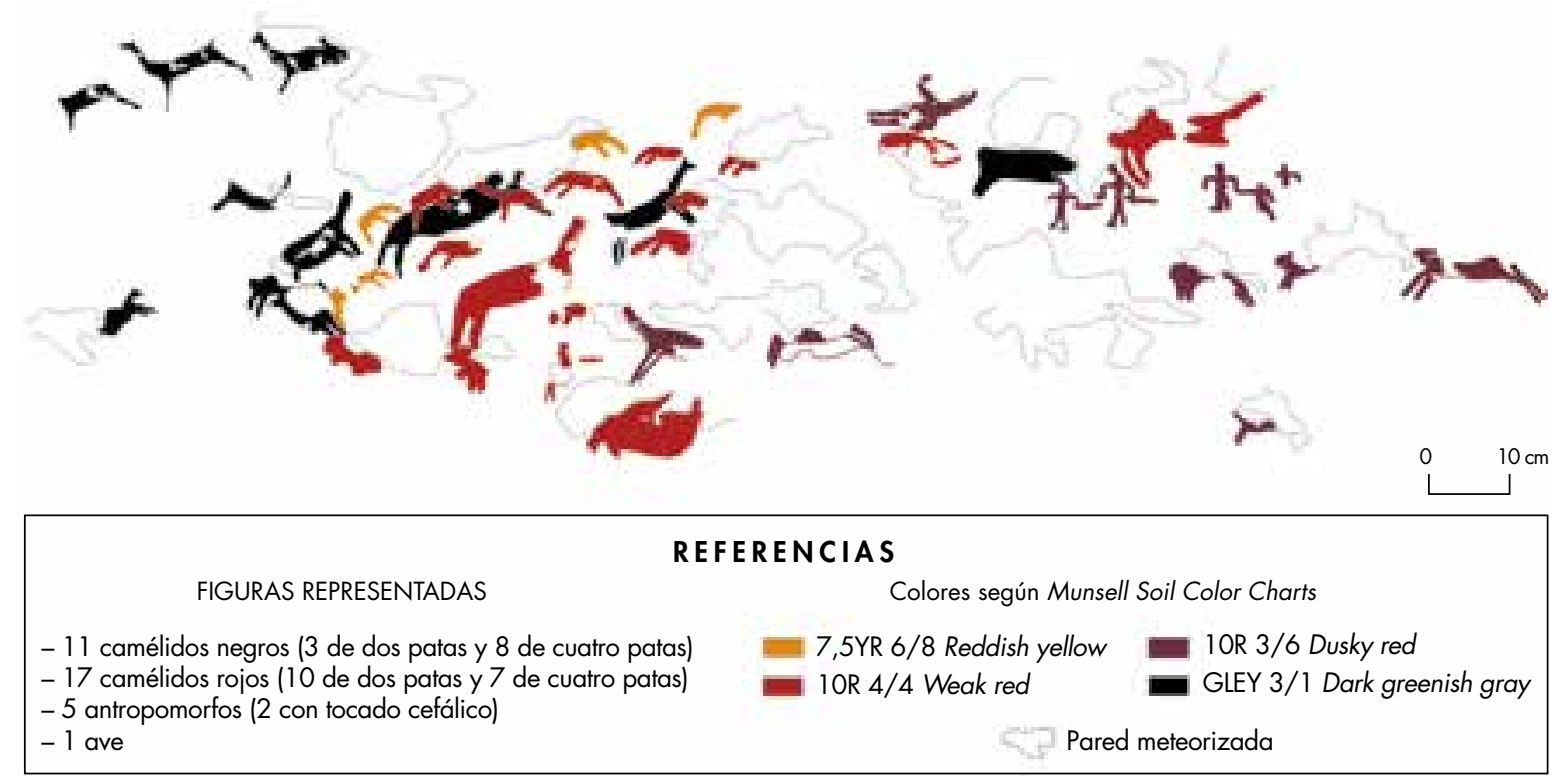

Figura 2. Las representaciones pictóricas de Hornillos 2.

Figure 2. Rock paintings at Hornillos 2. 


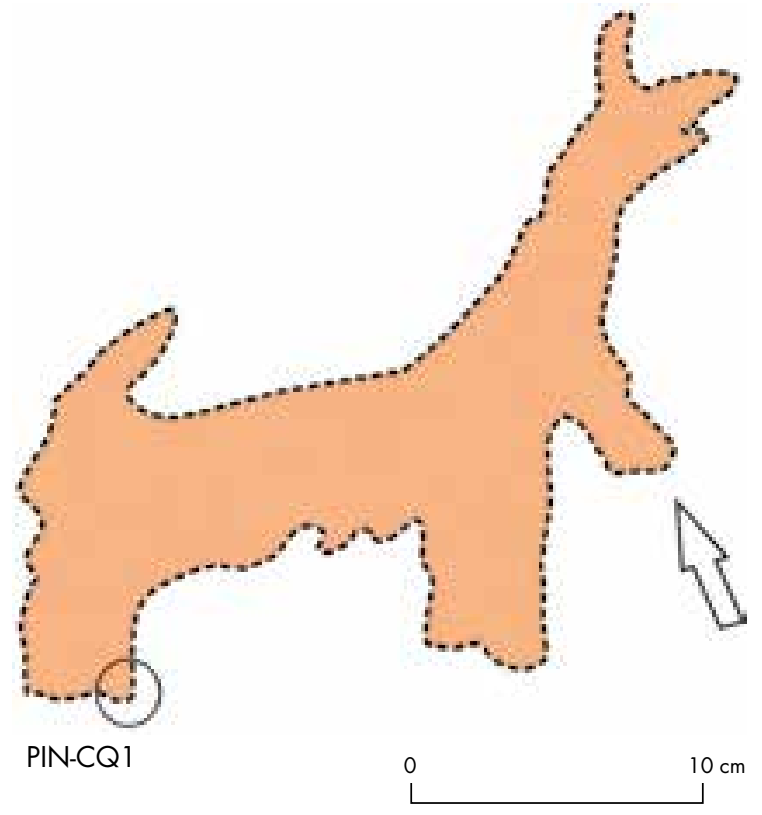

Figura 3. Figura de llama de Cueva Quispe. El círculo indica el punto de muestreo y la flecha señala el "faldón".

Figure 3. Picture of a llama at Cueva Quispe. The circle shows the sampling point and the arrow indicates the "faldon".
Los motivos pintados del sector 3 de TP son representaciones monocromas esquemático-figurativas de antropomorfos; algunas figuras están delineadas con trazos gruesos (de 10 a $15 \mathrm{~mm}$ ), otras tienen pigmento en su interior completando parcialmente los campos delimitados y también se distinguen figuras "fantasmas" por pérdida del pigmento y/o de la pared (fig. 4). En este panel se distinguen tres grupos: 1) siete antropomorfos incompletos (5R 3/6 Dark red), tienen cabeza $(3,5$ a $5 \mathrm{~cm})$, la parte superior del torso y los brazos/hombros bien definidos (ancho: $8 \mathrm{~cm}$ ), el cuerpo de algunos es corto y la cintura angosta; 2) dos antropomorfos (5R 3/8 Dark red) con piernas largas (largo total: 25 y $40 \mathrm{~cm}$ ), tres líneas paralelas verticales (ancho: $8 \mathrm{~cm}$ ) y cuatro puntos de $2 \mathrm{~cm}$ de diámetro; 3) dos antropomorfos ( $5 \mathrm{R} 2.5 / 6$ Dark red) con brazos largos y cuerpo-pierna indiferenciados (largo total: $32 \mathrm{y}$ $40 \mathrm{~cm}$ ) y vestigios de una figura corta de antropomorfo (¿niño?) entre ambas figuras largas (fig. 4). El estado de conservación es malo, incluye diversos trazos aislados de figuras indeterminables y presenta sectores con acreciones superficiales blancas y rojas sobre algunas de las figuras pintadas.
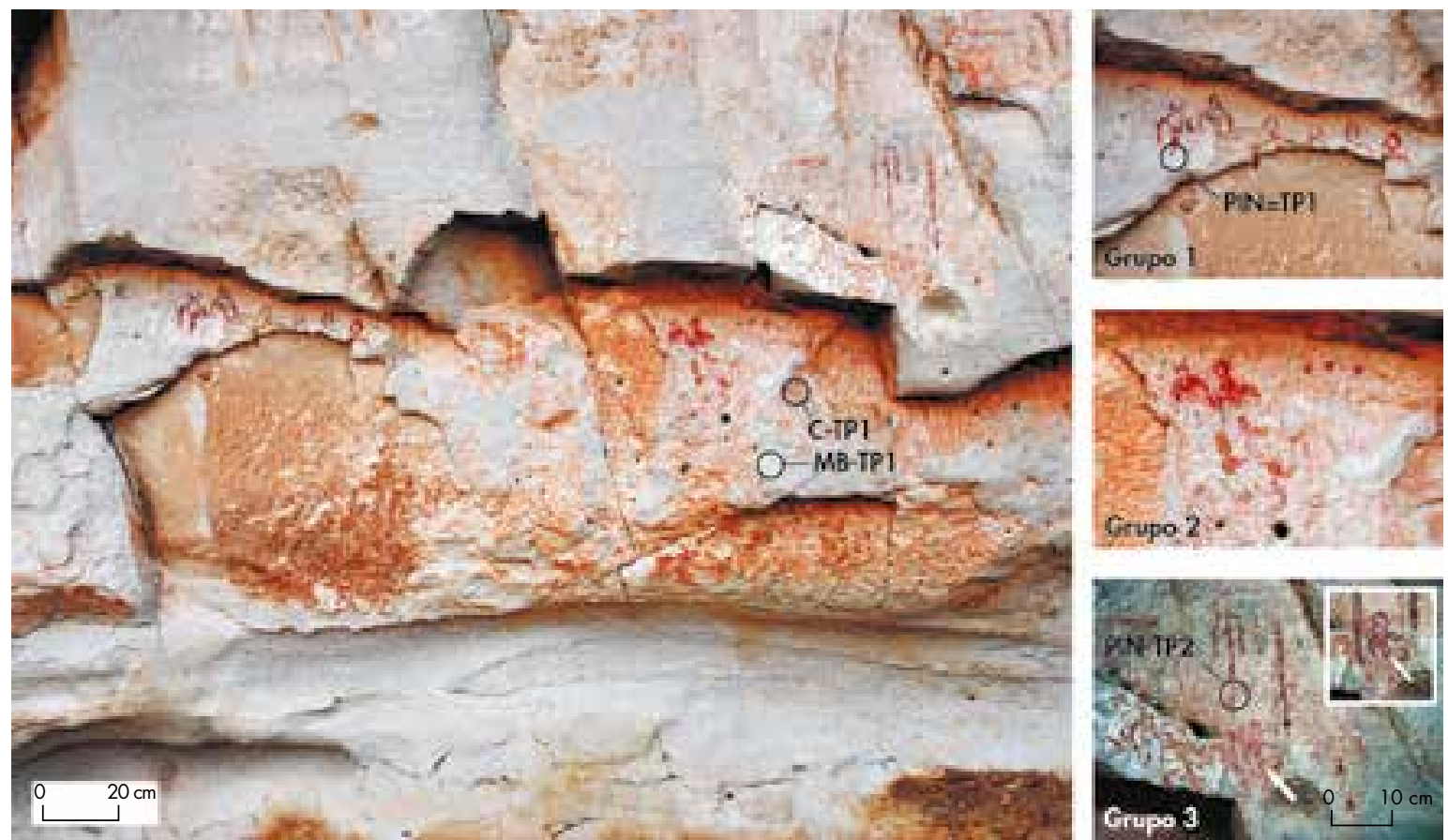

Figura 4. Panel pintado de Tres Pozos. A la derecha, detalle de los tres grupos diferenciados (los círculos señalan los puntos de muestreo). En la fotografía del Grupo 3 se ha incluido una imagen aumentada del antropomorfo de "cuerpo corto" (remarcado en línea negra) ubicado entre los dos antropomorfos de "cuerpo largo" (ver recuadro blanco).

Figure 4. Wall paintings at Tres Pozos. On the right, a detail of the three groups defined herein (sampling points indicated by circles). In the photo of Group 3, a close-up image of the "short-body" anthropomorphous figure (outlined in black), between two "long-body" ones (inside white square). 
a - Diagrama esquemático de la estructura cristalina de hematita $\left(\alpha-\mathrm{Fe}_{2} \mathrm{O}_{3}\right)$

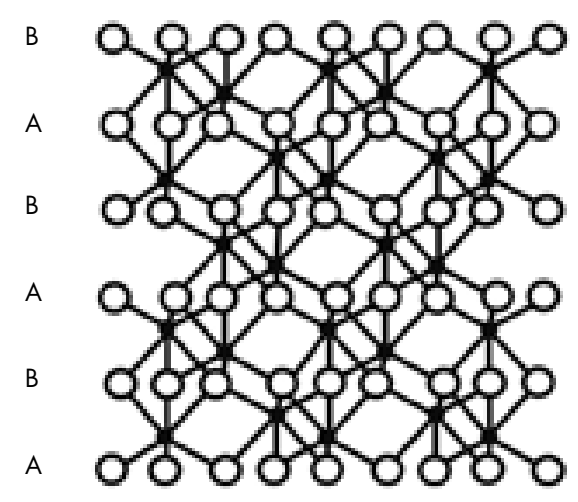

- Hierro O Oxígeno

Adaptado de Cudennec \& Lecerf (2006)

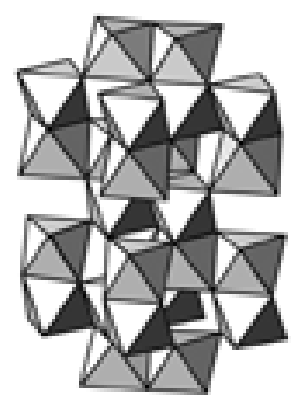

Adaptado de Cornell \& Schwertmann (1996) b - Diagrama esquemático de la estructura cristalina de esmectitas

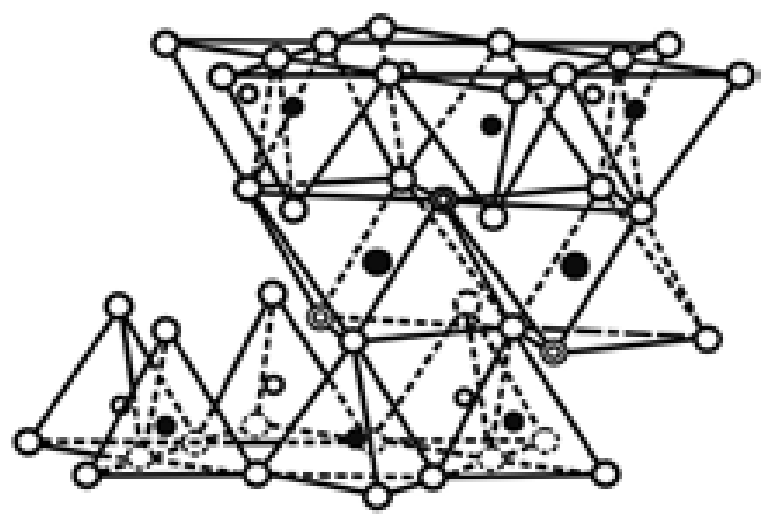

INTERCAPA

Agua y cationes intercambiables: $\mathrm{Na}^{+}, \mathrm{K}^{+}, \mathrm{Ca}^{2+}, \mathrm{Mg}^{2+}$

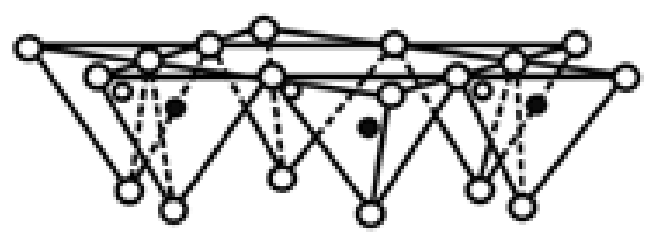

Oxígeno Oxhidrilos

Aluminio, hierro, magnesio

or Silicio, ocasionalmente aluminio

Adaptado de Murray (2007)

Figura 5. a) Estructura cristalina de la hematita; en la parte inferior, arreglo tridimensional de octaedros unidos por las caras cristalinas; b) Estructura cristalina de un mineral de arcilla del grupo de las esmectitas.

Figure 5. a) Crystal structure of hematite. At the bottom, a three-dimensional array of facet-sharing octahedral; b) Crystal structure of a smectitic clay mineral.

\section{LOS PIGMENTOS ROJIZOS NATURALES}

En la literatura se conoce a los materiales rojizos utilizados en las pinturas rupestres como pigmentos terrosos. Según el color fueron diferenciados en ocres (amarillo, rojo-anaranjado y marrón), tierras rojas, sienas (amarillo oscuro y marrón) y sombras (gris y castaño oscuro). Asimismo, en función del agente colorante, estos pigmentos naturales son de dos tipos: óxidos de hierro y pigmentos de base arcillosa o pigmentos arcillosos con un cromógeno en la estructura de la arcilla (Konta 1995; Hradil et al. 2003). ${ }^{2}$

El color es una propiedad fundamental de los minerales y está directamente relacionado con el carácter químico y estructural del material (Hradil et al. 2003: 223). ${ }^{3}$

En los pigmentos compuestos por óxidos férricos, el ion $\mathrm{Fe}^{3+}$ es el cromóforo que le imparte el color rojo al material. En la mayoría de los compuestos a los que, en general, nos referimos como óxidos férricos (en realidad, óxidos, hidróxidos u oxihidróxidos férricos), la unidad estructural básica está constituida por un octaedro con un ion $\mathrm{Fe}^{3+}$ central en coordinación seis con oxígenos $\left(\mathrm{O}^{2-}\right)$, oxidrilos $\left(\mathrm{OH}^{-}\right)$y/o agua $\left(\mathrm{H}_{2} \mathrm{O}\right)$ (Jang et al. 2007) formando un empaquetamiento con significante grado de enlaces covalentes Fe-O (Cornell \& Schwertmann 1996; Cudennec \& Lecerf 2006) (fig. 5a). ${ }^{4}$ Desde una perspectiva arqueológica y arqueométrica, la hematita $\left(\alpha-\mathrm{Fe}_{2} \mathrm{O}_{3}\right)$ es el pigmento rojo por excelencia por haber sido el más comúnmente empleado desde el Paleolítico en las pinturas del Viejo Mundo.

Los minerales de arcilla, en cambio, tienen una estructura compleja de hojas formada por tetraedros de sílice $\left(\mathrm{SiO}_{2}\right)$ y octaedros de alúmina $\left(\mathrm{Al}_{2} \mathrm{O}_{3}\right)\left(\mathrm{con} \mathrm{Si}{ }^{4+} \mathrm{y}\right.$ $\mathrm{Al}^{3+}$ centrales respectivamente) dispuestos en láminas o capas -combinadas- separadas por espacios libres denominados intercapas (fig. 5b). Los diferentes tipos de uniones químicas presentes en los filosilicatos (intermedias entre iónicas y covalentes, intermoleculares de Van der Waals y puente de hidrógeno) son las que imparten 
Tabla 1. Propiedades fisicoquímicas de la hematita y las arcillas de capa (Susques).

Table 1. Physical-chemical properties of hematite and clays from stratigraphic levels (Susques).

\begin{tabular}{|c|c|c|}
\hline Mineral & Hematita ${ }^{(*)}$ & Arcillas (especies determinadas en el estudio) ${ }^{(*)}$ \\
\hline Clasificación mineral & Óxido de hierro (férrico). & Filosilicatos alumínicos hidratados. \\
\hline \multirow{4}{*}{$\begin{array}{l}\text { Fórmula química } \\
\text { (general) }\end{array}$} & \multirow{4}{*}{$\begin{array}{c}\mathrm{Fe}_{2} \mathrm{O}_{3} \\
\text { Fe: } 70 \% \text { y O: } 30 \%\end{array}$} & $\begin{array}{c}\text { Esmectitas: } \\
(\mathrm{Ca}, \mathrm{Na}, \mathrm{H})(\mathrm{Al}, \mathrm{Mg}, \mathrm{Fe}, \mathrm{Zn})_{2}(\mathrm{Si}, \mathrm{Al})_{4} \mathrm{O}_{10}(\mathrm{OH})_{2}-\mathrm{nH}_{2} \mathrm{O}\end{array}$ \\
\hline & & Illita: $(\mathrm{K}, \mathrm{H})(\mathrm{Al}, \mathrm{Mg}, \mathrm{Fe})_{2}(\mathrm{Si}, \mathrm{Al})_{4} \mathrm{O}_{10}(\mathrm{OH})_{2}-\mathrm{nH}_{2} \mathrm{O}$ \\
\hline & & Clorita: $\left(\mathrm{Fe}^{2+}, \mathrm{Fe}^{3+}, \mathrm{Mg}\right)_{5} \mathrm{Al}\left(\mathrm{Si}_{3} \mathrm{Al}\right) \mathrm{O}_{10}(\mathrm{OH}, \mathrm{O})_{8}$ \\
\hline & & $\begin{array}{l}\text { Atapulgita (palygorskita): } \\
(\mathrm{Mg}, \mathrm{Al})_{2} \mathrm{Si}_{4} \mathrm{O}_{10}(\mathrm{OH}) \cdot 4\left(\mathrm{H}_{2} \mathrm{O}\right)\end{array}$ \\
\hline \multirow{4}{*}{ Sistema cristalino } & \multirow{4}{*}{$\begin{array}{l}\text { Hexagonal (romboédrico), } \\
\text { levemente distorsionado. }\end{array}$} & Esmectita (montmorillonita): monoclínico. \\
\hline & & Illita: monoclínico o triclínico (dioctaédrica o trioctaédrica). \\
\hline & & Clorita: monoclínico. \\
\hline & & Atapulgita (palygorskita): monoclínico. \\
\hline \multirow{4}{*}{ Color del mineral } & \multirow{4}{*}{$\begin{array}{l}\text { Rojo, rojo amarillento a marrón } \\
\text { rojizo, gris acero o negro de } \\
\text { hierro. }\end{array}$} & Esmectita (montmorillonita): blanco, gris, amarillo verdoso. \\
\hline & & Illita: blanco. \\
\hline & & Clorita: negro verdoso. \\
\hline & & Atapulgita (palygorskita): incoloro, blanco a blanco grisáceo. \\
\hline $\begin{array}{l}\text { Dureza } \\
\text { (escala de Mohs) }\end{array}$ & $5,5-6,5$ & 1 - 2,5 (variable según el tipo de mineral de arcilla). \\
\hline Plasticidad & $\begin{array}{l}\text { Nula, se comporta como un } \\
\text { material quebradizo. }\end{array}$ & $\begin{array}{c}\text { Mediante la adición de agua, la plasticidad puede ser alta } \\
\text { (en la esmectita) o mediana (en la illita). } \\
\text { Por exceso de agua, puede adquirir una consistencia } \\
\text { pegajosa (estado ideal en pintura facial/corporal); no } \\
\text { obstante, el agregado de otros materiales (minerales, } \\
\text { fragmentos líticos, conchillas, etc.) puede bajar ese grado de } \\
\text { plasticidad, no deseado en otros usos. }\end{array}$ \\
\hline $\begin{array}{l}\text { Merma } \\
\text { (por pérdida o } \\
\text { evaporación de agua } \\
\text { durante el secado) }\end{array}$ & $\begin{array}{l}\text { La hematita pura no contiene } \\
\text { oxidrilos ni agua. } \\
\text { Partiendo de una mezcla con } \\
\text { goethita, por calentamiento, esta } \\
\text { pierde el agua de composición y } \\
\text { se transforma en hematita (este } \\
\text { cambio estructural produce cierto } \\
\text { grado de contracción). }\end{array}$ & $\begin{array}{l}\text { Cuando las arcillas se secan o pierden el agua de intercapa, } \\
\text { se produce un encogimiento que se intensifica cuando } \\
\text { pierden el agua estructural o de composición (p. e., durante } \\
\text { la exposición al fuego en el proceso cerámico). }\end{array}$ \\
\hline Capacidad expansiva & No & $\begin{array}{c}\text { Las moléculas de agua (captadas en la intercapa } \\
\text { de la estructura) son fuertemente atraídas por las superficies } \\
\text { de los minerales de arcilla. La expansión es variable según } \\
\text { el tipo de arcilla: alta en las esmectitas (montmorillonita) y } \\
\text { baja/nula en la illita. }\end{array}$ \\
\hline Peso específico & $5,24-5,26$ & 2,60-2,90 (según el tipo de mineral de arcilla). \\
\hline \multirow{3}{*}{ Densidad } & \multirow{3}{*}{$4,9-5,3 \mathrm{~g} / \mathrm{cm}^{3}$} & Esmectita (montmorillonita): $2,35 \mathrm{~g} / \mathrm{cm}^{3}$ \\
\hline & & Illita: $2,75 \mathrm{~g} / \mathrm{cm}^{3}$ \\
\hline & & Atapulgita (palygorskita): $2,15 \mathrm{~g} / \mathrm{cm}^{3}$ \\
\hline Solubilidad & $\begin{array}{l}\text { Es baja en agua, sin embargo, } \\
\text { se puede hidratar e hidrolizar. } \\
\text { Ligeramente soluble en ácido. }\end{array}$ & En agua se hidrolizan y en ácidos se descomponen. \\
\hline
\end{tabular}

(*) Los datos detallados fueron tomados de Lambe \& Whitman (1969), Dana \& Ford (1973), Cornell \& Schwertmann (1996) y Meunier (2005). 
Tabla 2. Composición mineral de las pinturas rojas de Hor2, CQ, TP y cuero de Inca Cueva. Referencias: tr (traza), en cursiva (cromógeno).

Table 2. Mineral composition of red paints from Hor2, CQ, TP and Inca Cueva hide. References: $\operatorname{tr}$ (trace), in italics (chromogen).

\begin{tabular}{|c|c|c|c|}
\hline Muestra & Sitio & Minerales (DRX) & Cromóforo (EDS) \\
\hline PIN-M11 & Hornillos 2 & $\begin{array}{l}\text { Yeso }\left(\mathrm{CaSO}_{4} \cdot 2 \mathrm{H}_{2} \mathrm{O}\right) \text { (mayoritario), cuarzo (escaso), } \\
\text { plagioclasa, muscovita y hematita }\left(\alpha-\mathrm{Fe}_{2} \mathrm{O}_{3}\right)(\mathrm{tr}) \text {. }\end{array}$ & $\mathrm{Fe}$ \\
\hline PIN-M12 & Hornillos 2 & $\begin{array}{l}\text { Yeso (mayoritario), plagioclasa (abundante), } \\
\text { cuarzo, muscovita (tr) y probable clorita. }\end{array}$ & $\mathrm{Fe}$ \\
\hline PIN-M13 & Hornillos 2 & $\begin{array}{l}\text { Yeso (mayoritario), cuarzo, plagioclasa, muscovita (tr), } \\
\text { probable clorita y hematita (significativa). }\end{array}$ & $\mathrm{Fe}$ \\
\hline PIN-M14 & Hornillos 2 & $\begin{array}{l}\text { Yeso (mayoritario), cuarzo, plagioclasa, muscovita, } \\
\text { probables clorita y hematita. }\end{array}$ & $\mathrm{Fe}$ \\
\hline PIN-CQ1 & Cueva Quispe & Yeso (mayoritario), cuarzo y plagioclasa (tr), bematita. & $\mathrm{Fe}$ \\
\hline PIN-CQ2 & Cueva Quispe & Yeso (mayoritario), plagioclasa y cuarzo (tr), hematita. & $\mathrm{Fe}$ \\
\hline PIN-TP1 & Tres Pozos & $\begin{array}{l}\text { Anhidrita }\left(\mathrm{CaSO}_{4}\right) \text { (mayoritaria), cuarzo y plagioclasa } \\
\text { (escasos), probable calcita, hematita. }\end{array}$ & $\mathrm{Fe}$ \\
\hline PIN-TP2 & Tres Pozos & $\begin{array}{l}\text { Yeso (mayoritario), calcita (abundante), plagioclasa, } \\
\text { cuarzo, mica y hematita. }\end{array}$ & $\mathrm{Fe}$ \\
\hline ICc4-432 & Inca Cueva (c4) & $\begin{array}{l}\text { Cuarzo (mayoritario), feldespato potásico, } \\
\text { illita (mica) (tr) y hematita (minoritaria). }\end{array}$ & $\mathrm{Fe}$ \\
\hline
\end{tabular}

a estos minerales la estructura "laminar". 5 Además, en las hojas de los minerales de arcilla se producen sustituciones parciales de algunos elementos en función del radio iónico y de las cargas eléctricas (p. e., $\mathrm{Fe}^{3+}$ por $\mathrm{Al}^{3+}$ en los octaedros). Como resultado, las arcillas pueden contener el cromóforo $\mathrm{Fe}^{3+}$ en su estructura cristalina, pero, por lo general, es el óxido férrico el cromógeno de algunas arcillas resultantes de mezclas terrígenas (Chamley 1989; Cornell \& Schwertmann 1996).

La simple comparación de las propiedades de ambos grupos minerales (óxidos férricos y arcillas) realza el potencial fisicoquímico que cada uno aportó a las pictografías, tecnofacturas en cuero (u otros materiales) o a la pintura facial y corporal. En la Tabla 1 se reseñan algunas de las propiedades que nos interesa destacar de la hematita y las arcillas -esmectitas, illita, clorita y palygorskita- encontradas en capa en los sitios estudiados.

\section{TÉCNICAS ANALÍTICAS}

La técnica analítica de base empleada en la determinación de las pinturas rojas y los pigmentos de capa fue difractometría de rayos X (DRX) complementada con microscopia electrónica de barrido y espectrometría de rayos X por dispersión de energía (MEB-EDS). Como técnica microanalítica para la determinación de las sustancias orgánicas se aplicó espectroscopia infrarroja con transformada de Fourier (FT-IR) y cromatografía de gases / espectrometría de masa (GC-MS). ${ }^{6}$

\section{MATERIALES ESTUDIADOS Y RESULTADOS ANALITICOS}

En artículos previos (Yacobaccio et al. 2008, 2011, 2012) publicamos los resultados analíticos (química inorgánica y orgánica) de pigmentos, pinturas y roca de caja de Hor2 y CQ (Tablas 2, 3 y 4). En este trabajo presentamos las determinaciones de pinturas sobre pared de TP y de las acreciones superficiales (rojizas y blancas) y la roca de caja, además de la composición de la pintura roja de un cuero de Inca Cueva (c4) y la de un sedimento rojizo (LV1) alóctono ( $\mathrm{N}_{\mathrm{TOTAL}}$ : 34 muestras) (Tablas 2, 3 y 4).

La muestra ICc4-432 de Inca Cueva (c4) (capa 2, 10.620-9230 AP; ver Aschero \& Podestá 1986) corresponde a un cuero curtido de vicuña (con pelo) con pintura roja aplicada (el número de muestra de la pintura es homólogo). El cuero tiene forma de cinta ligeramente triangular (largo: $10 \mathrm{~cm}$; máximo ancho: 
Tabla 3. Composición mineral de los pigmentos de capa de Hor2 y CQ, de las acreciones superficiales de TP y del sedimento de Laguna Vilama. Referencias: tr (traza), en cursiva (cromógeno).

Table 3. Mineral composition of pigments from stratigraphic levels at Hor2 and CQ, superficial accretions at TP and sediment from Laguna Vilama. References: tr (trace), in italics (chromogen).

\begin{tabular}{|c|c|c|c|}
\hline Muestra & Sitio & Minerales (DRX) & $\begin{array}{l}\text { Cromóforo } \\
\text { (EDS) }\end{array}$ \\
\hline PIG-M1 & Hornillos 2 & $\begin{array}{l}\text { Cuarzo y dolomita (mayoritarios), calcita, plagioclasa, } \\
\text { arcillas (probable esmectita) y hematita (tr). }\end{array}$ & $\mathrm{Fe}$ \\
\hline PIG-M2 & Hornillos 2 & $\begin{array}{c}\text { Cuarzo y plagioclasa (abundantes), palygorskita, clorita, } \\
\text { probables fosfatos y bematita (tr). }\end{array}$ & $\mathrm{Fe}$ \\
\hline PIG-M3 & Hornillos 2 & $\begin{array}{c}\text { Carbonato }\left(\mathrm{CO}_{3}\right)^{-2} \text {, palygorskita, clorita; cuarzo y plagioclasa (tr) } \\
\text { y bematita. }\end{array}$ & $\mathrm{Fe}$ \\
\hline PIG-M4 & Hornillos 2 & $\begin{array}{l}\text { Hematita, goethita }[\alpha-\mathrm{FeO}(\mathrm{OH})] \text { y akaganeita }[\beta-\mathrm{FeO}(\mathrm{OH})] \\
\text { (mayoritarias), illita y fosfato de calcio }(\mathrm{tr}) \text {. }\end{array}$ & $\mathrm{Fe}$ \\
\hline PIG-M5 & Hornillos 2 & Cuarzo (abundante), plagioclasa (tr), illita, clorita y bematita. & $\mathrm{Fe}$ \\
\hline PIG-M6 & Hornillos 2 & Hematita (mayoritaria, casi pura). & $\mathrm{Fe}$ \\
\hline PIG-M7 & Hornillos 2 & Hematita y goethita (mayoritarias), cuarzo y micas (escasos). & $\mathrm{Fe}$ \\
\hline PIG-M8 & Hornillos 2 & Hematita (mayoritaria), goethita, cuarzo y micas (tr). & $\mathrm{Fe}$ \\
\hline PIG-CQ1-2-3-4 & Cueva Quispe & Cuarzo, plagioclasa, clorita y bematita (tr). & $\mathrm{Fe}$ \\
\hline PIG-CQ5-6-7-8 & Cueva Quispe & Cuarzo, plagioclasa (tr), illita (tr), clorita (tr) y bematita (tr). & $\mathrm{Fe}$ \\
\hline PIG-CQ12-13 & Cueva Quispe & Cuarzo, plagioclasa (tr), illita (tr) y clorita (tr). & $\mathrm{Fe}$ \\
\hline PIG-CQ27 & Cueva Quispe & Cuarzo, plagioclasa y bematita (tr). & $\mathrm{Fe}$ \\
\hline PIG-CQ28 & Cueva Quispe & $\begin{array}{l}\text { Cuarzo, feldespato alcalino, plagioclasa (tr), illita/mica } \\
\text { y bematita }(\mathrm{tr}) .\end{array}$ & $\mathrm{Fe}$ \\
\hline CR-TP-1 & Tres Pozos & $\begin{array}{l}\text { Anhidrita (mayoritaria) y yeso, cuarzo y plagioclasa (escasos), } \\
\text { calcita, mica y hematita. }\end{array}$ & $\mathrm{Fe}$ \\
\hline MB-TP-1 & Tres Pozos & $\begin{array}{l}\text { Cuarzo y plagioclasa (abundantes), boratos (abundantes) } \\
\text { y probable yeso. }\end{array}$ & - \\
\hline LV1 & Lag. Vilama & $\begin{array}{c}\text { Yeso (mayoritario), calcita (abundante), probables zeolitas } \\
\text { y hematita (minoritaria). }\end{array}$ & $\mathrm{Fe}$ \\
\hline
\end{tabular}

$2 \mathrm{~cm})$ y la pintura $(7,5 \mathrm{R} 4 / 6 \mathrm{Red})$ cubre gran parte del lado interno (fig. 6a). En el sitio se halló un segundo cuero (ICc4-s/n) de forma irregular $(13$ x $18 \mathrm{~cm})$ con un "ojal"; este indicaría que el cuero fue utilizado para la talla de material lítico (fig. 6b).

El sedimento rojizo (LV1, color: 5R 4/8 Red) hallado en el Puesto Cooperativa Vilama, en las inmediaciones de la laguna Vilama a $4500 \mathrm{msnm}$ ( ca. $80 \mathrm{~km}$ lineales al NO de Susques) es un compuesto terrígeno (pigment pan) de consistencia pastosa. Por las condiciones del hallazgo, debió ser almacenado para ser utilizado en alguna actividad. Si bien este hallazgo se ubica fuera del área analizada, su estudio resultó de sumo interés para la investigación (ver Tablas 3 y 4).

Los análisis de DRX y EDS realizados sobre las pinturas de los tres sitios dieron variadas proporciones de hematita (cromógeno) y hierro (cromóforo). En estas pinturas se registró yeso mayoritario (la carga), excepto en una muestra con anhidrita mayoritaria (PIN-TP1), y proporciones menores de otros minerales (Tablas 2 y 4). Los estudios efectuados sobre los pigmentos de capa de Hor2 y CQ indican diversidad composicional, distinguiéndose los pigmentos de base arcillosa y los óxidos de hierro. Estos últimos -hematita, goethita y akaganeíta- mostraron también proporciones variables de silicatos, filosilicatos, carbonatos y fosfatos (Tablas 3 y 4). El análisis del sedimento rojizo de la laguna Vilama (LV1) arrojó yeso, calcita, probables zeolitas (minerales secundarios con Fe y Mg) y hematita (Tablas 3 y 4), y los estudios realizados sobre la pintura roja del cuero (ICc4-432) de Inca Cueva indicaron una asociación de silicatos (mayoritarios) con hematita y arcilla micácea (minoritarios) (Tablas 2 y 4 ).

Los estudios de los componentes orgánicos de las pinturas y los pigmentos de capa de Hor 2 realizados mediante cromatografía gaseosa y espectrometría de 
Tabla 4. Análisis EDS (elementos) en pinturas, pigmentos e ignimbrita local -roca de caja- (\% atómico desde Na a U). Referencias: IC (Inca Cueva), LV (Laguna Vilama); osc (oscuro), cl (claro), roj (rojizo).

Table 4. Elemental composition (\%) of paints, pigments and local ignimbritic rock by EDS technique (detectability: Na to U). References: IC (Inca Cueva), LV (Laguna Vilama); osc (dark), cl (light), roj (reddish).

\begin{tabular}{|c|c|c|c|c|c|c|c|c|c|c|c|c|c|}
\hline Sitio & \multicolumn{2}{|c|}{ Descripción del material } & Si & $\mathrm{Ti}$ & Al & $\mathrm{Fe}$ & $\mathrm{Mg}$ & $\mathrm{Ca}$ & $\mathrm{Na}$ & $\mathrm{K}$ & $\mathrm{Cl}$ & $\mathbf{P}$ & $\mathrm{S}$ \\
\hline \multirow{13}{*}{$\begin{array}{c}\text { HORNILLOS } \\
2\end{array}$} & PIG-M1 & Pigmento rojo $(\mathrm{cl})$ & 23,85 & - & 9,76 & 4,02 & 21,82 & 37,37 & - & 3,20 & - & - & - \\
\hline & PIG-M2 & Pigmento rojo & 45,58 & - & 26,95 & 5,60 & 3,48 & 8,39 & 0,91 & 3,88 & - & 0,48 & - \\
\hline & PIG-M3 & Pigmento amarillo & 49,35 & - & 16,15 & 29,53 & - & 0,57 & - & 4,40 & - & - & - \\
\hline & PIG-M4 & Pigmento rojo & 13,75 & - & 7,45 & 74,23 & - & 1,70 & - & 1,27 & - & 1,61 & - \\
\hline & PIG-M5 & Pigmento rojo & 38,96 & - & 18,97 & 33,53 & 2,70 & 1,08 & - & 4,76 & - & - & - \\
\hline & PIG-M6 & Pigmento rojo (osc) & 3,37 & - & 2,43 & 94,21 & - & - & - & - & 0,50 & - & - \\
\hline & PIG-M7 & Pigmento rojo & 14,43 & - & 8,10 & 68,60 & - & 2,24 & 1,36 & 2,49 & - & 1,93 & - \\
\hline & PIG-M8 & Pigmento rojo (cl) & 17,54 & - & 8,03 & 72,69 & - & 0,32 & - & 1,42 & - & - & - \\
\hline & PIN-M11 & Pintura roja $(\mathrm{cl})$ & 20,98 & - & 8,10 & 2,82 & 3,99 & 29,41 & - & 1,72 & - & 2,34 & 30,67 \\
\hline & PIN-M12 & Pintura ocre (osc) & 22,06 & - & 9,21 & 3,35 & 3,44 & 21,93 & 6,65 & 3,67 & - & 1,24 & 28,97 \\
\hline & PIN-M13 & Pintura ocre $(\mathrm{cl})$ & 19,70 & 0,82 & 8,03 & 14,64 & 6,47 & 19,99 & 3,74 & 3,33 & - & 1,48 & 21,02 \\
\hline & PIN-M14 & Pintura roja (cl) & 21,60 & - & 9,74 & 2,69 & 5,62 & 23,26 & 3,03 & 2,33 & - & 2,68 & 29,08 \\
\hline & M16 (roca) & Ignimbrita local & 61,03 & 0,21 & 14,28 & 5,51 & 3,94 & 3,02 & 3,75 & 4,76 & 0,74 & - & 2,42 \\
\hline \multirow{14}{*}{$\begin{array}{l}\text { CUEVA } \\
\text { QUISPE }\end{array}$} & PIG-CQ1 & Pigmento ocre & 60,87 & 0,77 & 23,48 & 4,39 & 2,50 & - & - & 7,82 & - & - & 0,25 \\
\hline & PIG-CQ2 & Pigmento ocre & 64,72 & 0,70 & 20,83 & 4,48 & 2,43 & - & - & 6,84 & - & - & - \\
\hline & PIG-CQ3 & Pigmento ocre & 51,57 & 0,56 & 23,00 & 10,15 & 3,36 & 1,22 & - & 6,06 & 1,04 & 1,38 & 2,12 \\
\hline & PIG-CQ4 & Pigmento ocre & 56,93 & 1,22 & 25,41 & 4,73 & 2,40 & - & - & 9,32 & - & - & - \\
\hline & PIG-CQ5 & Pigmento ocre & 57,53 & 0,60 & 19,73 & 14,79 & 3,48 & 1,05 & - & 5,14 & 0,50 & - & 0,71 \\
\hline & PIG-CQ6 & Pigmento ocre & 85,62 & - & 6,89 & 3,19 & 2,92 & 0,77 & - & 1,93 & 1,14 & - & 1,49 \\
\hline & PIG-CQ7 & Pigmento ocre & 64,88 & 0,33 & 15,20 & 9,83 & 5,15 & 0,84 & - & 2,82 & 0,74 & - & 1,12 \\
\hline & PIG-CQ8 & Pigmento rojo & 52,83 & 0,57 & 23,64 & 10,45 & 2,36 & 1,67 & - & 6,17 & 0,65 & - & 2,21 \\
\hline & PIG-CQ12 & Pigmento ocre & 53,61 & 0,64 & 22,91 & 11,43 & 3,75 & - & - & 6,26 & - & - & - \\
\hline & PIG-CQ13 & Pigmento ocre & 46,45 & 0,59 & 24,86 & 13,91 & 2,47 & 0,96 & - & 5,85 & 0,92 & 2,16 & 1,87 \\
\hline & PIG-CQ27 & Pigmento rojo & 54,80 & 0,57 & 22,86 & 9,09 & 3,53 & 0,71 & - & 6,37 & 0,81 & 1,02 & 0,44 \\
\hline & PIG-CQ28 & Pigmento rojo & 57,76 & 0,07 & 18,71 & 7,43 & 1,78 & 1,00 & - & 11,65 & - & - & 1,61 \\
\hline & PIN-CQ1 & Pintura roja $(\mathrm{cl})$ & 29,88 & 0,27 & 11,55 & 2,84 & 4,27 & 25,57 & 1,11 & 2,70 & 8,41 & - & 13,39 \\
\hline & PIN-CQ2 & Pintura roja $(\mathrm{cl})$ & 34,25 & 1,48 & 14,49 & 6,97 & 6,65 & 16,96 & - & 4,71 & 6,13 & - & 8,35 \\
\hline \multirow{5}{*}{$\begin{array}{c}\text { TRES } \\
\text { POZOS }\end{array}$} & PIN-TP1 & Pintura roja (osc) & 33,39 & 0,49 & 11,29 & 7,17 & 1,88 & 11,58 & 11,41 & 4,84 & - & - & 17,96 \\
\hline & PIN-TP2 & Pintura roja (osc) & 35,94 & - & 10,70 & 2,37 & - & 17,72 & 6,40 & 4,55 & - & - & 22,33 \\
\hline & CR-TP-1 & Acreción rojiza & 31,69 & 1,17 & 10,55 & 9,36 & - & 20,77 & - & 5,33 & - & - & 21,16 \\
\hline & MB-TP-1 & Acreción blanca & 39,33 & - & 11,29 & 2,04 & - & 10,13 & 12,37 & 5,19 & - & - & 19,65 \\
\hline & TP-Roca & Ignimbrita local & 57,71 & 0,58 & 15,32 & 2,58 & 1,82 & 6,57 & 3,40 & 6,58 & - & - & 5,83 \\
\hline I C & ICc4-432 & Pintura roja s/cuero & 47,09 & 2,42 & 18,98 & 11,91 & 10,09 & - & - & 9,52 & - & - & - \\
\hline LV & LV1 & $\begin{array}{c}\text { Sedimento fino } \\
\text { rojizo (¿pigmento?) }\end{array}$ & 19,42 & - & 1,56 & 13,79 & 15,73 & 37,00 & - & - & - & - & 12,47 \\
\hline
\end{tabular}



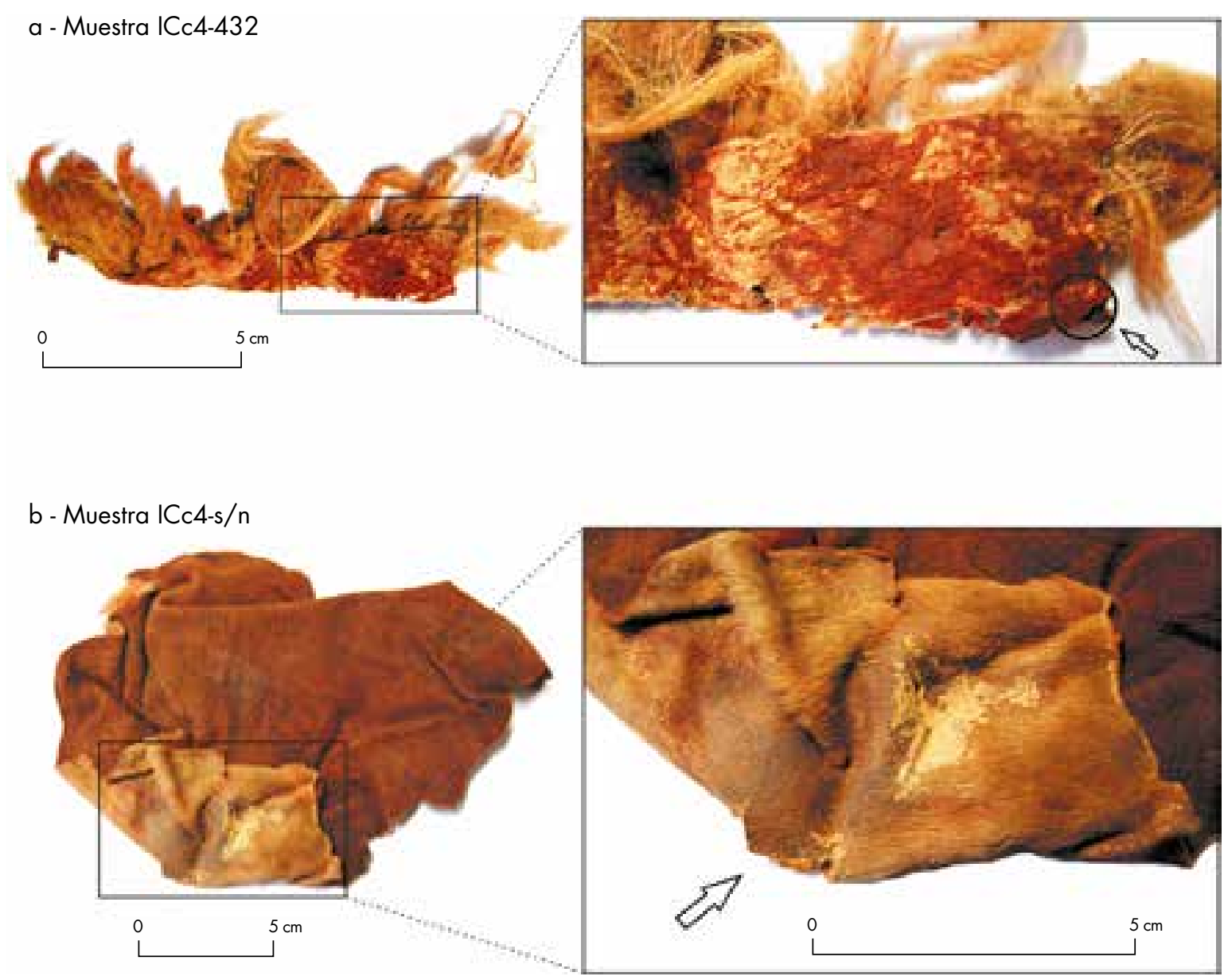

Figura 6. Cueros de vicuña de Inca Cueva (c4) (Aschero 1984). a) Cuero con pintura roja (el círculo indica el punto de muestreo); b) Cuero con ojal para tallar lítico (la flecha señala el ojal).

Figure 6. Vicuña hides from Inca Cueva (c4) (Aschero 1984). a) Hide bearing red paint (sampling point indicated by circles); b) Piece of bide with a bole for carving stones (hole is indicated by an arrow).

masa permitieron establecer la naturaleza del material usado como ligante (Vázquez 2008; Yacobaccio et al. 2008, 2012). Los ácidos grasos identificados en las pinturas de Hor2 apuntan a una grasa animal degradada. Algunas muestras contenían lípidos compuestos por ácido palmítico (C16:0), ácido esteárico (C18:0) y ácido oleico (C18:1), además de ácidos grasos impares (de 15 y 17 carbonos), estos últimos son característicos de actividad microbiana que podría asociarse con animales rumiantes, probablemente, camélidos silvestres. En cambio, las muestras de pinturas y pigmentos de CQ y TP solo presentaron vestigios de lípidos cuyo análisis por cromatografía gaseosa indicó la presencia únicamente de ácido palmítico (C16:0) y ácido esteárico (C18:0), hecho que impidió establecer alguna hipótesis sobre el empleo de ligantes orgánicos. Los espectros infrarrojos realizados sobre los dos cueros dieron señales de las proteínas típicas del cuero (bandas a 1636 y $1543 \mathrm{~cm}^{-1}$ ) y la pintura roja (ICc4-432) no aportó señales de lípidos.

\section{DISCUSIÓN}

La hematita es el pigmento de las pinturas rojas de Hor2, CQ y TP. En cambio, los pigmentos de capa de Hor2 y CQ se corresponden con las dos especies minerales mencionadas: 1) óxidos y oxihidróxidos de hierro -hematita, goethita y akaganeíta- y 2) pigmentos de base arcillosa -esmectita, clorita, illita, illita/mica y palygorskita- mezclados con silicatos, carbonatos, fosfatos y hematita. ${ }^{7}$

Las pinturas de Hor2, CQ y TP (grupo 3) contienen abundante yeso $\left(\mathrm{CaSO}_{4} \cdot 2 \mathrm{H}_{2} \mathrm{O}\right)$, mientras que la pintura 
de TP (grupo 1) tiene anhidrita $\left(\mathrm{CaSO}_{4}\right)$ en lugar de yeso; cabe mencionar que ninguno de los pigmentos de capa contiene estos minerales evaporíticos (Tablas 3 y 4 ). ${ }^{8}$ Las pinturas de Hor 2 analizadas, tres pigmentos de capa de Hor2 y tres de CQ muestran porcentajes minoritarios de fósforo (P), elemento no detectado en la roca de caja local (Tabla 4). En una publicación anterior (Yacobaccio et al. 2012) planteamos que el contenido de fósforo en las pinturas de Hor2 provendría del agregado de hueso molido, descartándose la contaminación in situ; en cambio, las pinturas de CQ y TP no contienen fosfatos de calcio ni vestigios de fósforo (Tabla 4).

A su vez, las acreciones rojizas y blancas detectadas sobre las paredes de TP son una mezcla de minerales evaporíticos, carbonatos, silicatos y hematita en CR-TP1, con boratos en MB-TP1. Los elementos detectados son concordantes con las especies minerales determinadas, excepto en MB-TP1, cuyo análisis adicional con un equipo EDS que discrimina boro no captó dicho elemento (límite de detección del equipo: 0,1\% del total). Los análisis efectuados sobre las acreciones superficiales de TP plantean una situación particular puesto que ni la roca ignimbrítica ni las pinturas sobre pared contienen trazas de boro. Las acreciones blancas relevadas sobre la pared ignimbrítica podrían deberse a procesos de contaminación ambiental; el sitio se ubica a $30 \mathrm{~km}$ al noroeste de las Salinas Grandes (fuente de boratos, cloruros y litio) y los vientos locales pudieron transportar los boratos detectados por difracción en MB-TP-1.

La pintura roja del cuero (ICc4-432) de Inca Cueva (c4) está constituida por óxido férrico (hematita) en una matriz compuesta principalmente por cuarzo y feldespato potásico y cantidades menores de illita (mica) atribuible a material arcilloso. Es un material que comparte las propiedades de la hematita y las arcillas; el contenido de $\mathrm{Fe}(11,91 \%)$ es compatible con el de las arcillas rojas, en este caso, con tenores equivalentes de $\mathrm{Mg}$ y K (10,09\% y 9,52\% respectivamente) (ver Tabla 4). Esta combinación de componentes es propia de los "ocres" naturales (earthy pigments o clayey ochres) aunque también puede ser el resultado de mezclar y moler mecánicamente materiales de diferente origen (Audouin \& Plisson 1982; Hradil et al. 2003).

La caracterización fisicoquímica del sedimento rojizo de laguna Vilama (LV1) aportó resultados inesperados porque a priori parecía un pigmento arcilloso. Se trata de un material compuesto por yeso, calcita, zeolitas y hematita (Tablas 3 y 4). Los resultados del análisis por EDS son concordantes con los minerales referidos; el calcio (37\%) participa en la composición de yeso $\left(\mathrm{CaSO}_{4} \cdot 2 \mathrm{H}_{2} \mathrm{O}\right)$ y calcita $\left(\mathrm{CaCO}_{3}\right)$, y el Fe $(13,8 \%)$ le concede el color rojo intenso. A su vez, los análisis de química orgánica indicaron vestigios de ácidos grasos provenientes de lípidos. Las investigaciones de Ballivian y Risacher (1981), López y colaboradores (1999) y Ovejero Toledo y colaboradores (2009) en salares del norte de Chile y del suroeste de Bolivia informan que esos sistemas salinos -continentalesposeen yeso y calcita (mayoritarios) en asociación con cloruros, boratos y sulfatos (en proporciones variables) y están intercalados con arcillas rojas. En la Puna jujeña, el salar de Cauchari y el depocentro de San Juan de Oro también presentan sedimentos finos rojos alternantes con carbonatos lacustres y yeso (Alonso 2006). Estas paragénesis minerales son similares a la determinada en el sedimento de Laguna Vilama (LV1) (Tablas 3 y 4). Por tal motivo, consideramos que LV1 es un producto natural, quizás, almacenado para ser utilizado en alguna actividad no alfarera por carecer de minerales de arcilla.

Los resultados analíticos han puesto de manifiesto el contraste composicional entre las pinturas de los tres sitios. En Hor2, las pinturas parecen haber sido preparadas con una mezcla de pigmento, yeso, hueso molido y ligante orgánico de origen animal. Sugerimos que la materia orgánica, quizás se trate de médula ósea, pudo haber ingresado a la pintura conjuntamente con el hueso molido. En cambio, la composición de las pinturas de CQ y TP plantea dos posibilidades: 1) se aplicaron "recetas" -mezcla de pigmento, yeso o anhidrita y, quizás, agua como ligante- o 2) se usaron materias primas naturales semejantes al material de Laguna Vilama, en ambos casos, sin agregado de hueso molido. Los vestigios de ácidos grasos detectados son insuficientes para establecer la naturaleza del ligante. El caso particular de las pinturas de TP permite plantear, como mínimo, dos eventos de realización con recetas y fuentes diferentes, por un lado, hematita y anhidrita (carga) y, por el otro, hematita y yeso (carga) en los grupos 1 y 3 respectivamente.

Si no son agregados terrosos, los óxidos de hierro son duros y suelen ser ásperos al tacto, tienen buena resistencia química (son usualmente insolubles en agua), tienen gran capacidad colorante y son resistentes a la luz y a la temperatura. Por el contrario, las arcillas puras son blandas y suaves y al mezclarse con agua resultan plásticas y maleables; tienen capacidad pigmentante pero se deterioran rápidamente sin tratamiento térmico (Tabla 1). Las propiedades intrínsecas de los minerales -basicidad, fuerza de unión con el oxígeno, presencia de iones con más de un estado de oxidación, grado de compactación cristalina y tamaño de grano de los cristales- determinan, en parte, su estabilidad frente a factores de alteración extrínsecos. Es por ello que, en nuestro análisis, sobre por qué los óxidos de hierro, y no las arcillas, fueron utilizados de modo tan específico en las pinturas rupestres de los tres sitios de Susques (como también en las pictografías 
de diferentes regiones argentinas) no pueden dejar de evaluarse los procesos de meteorización intervinientes.

Bajo condiciones xéricas como las de la Puna jujeña, prevalecen los procesos de meteorización física (mecánica) que fragmentan y desintegran los materiales rocosos superficiales por descompresión, exfoliación, congelamiento y deshielo. Estos son favorecidos por factores climáticos y ambientales como la variación térmica diaria y estacional, las temperaturas por encima y por debajo del punto de fusión del hielo, la incidencia solar, los vientos y la ausencia de vegetación, además del relieve y la red de drenaje. En la región de estudio, estos procesos han incidido negativamente sobre los paneles pintados de los tres sitios produciendo intensa exfoliación por termoclastismo, con pérdida de considerables superficies pintadas. A su vez, y a pesar del clima semiárido puneño, el intemperismo químico también actúa sobre los materiales, siendo el agua el principal agente que degrada los minerales: los descompone y transforma. Este proceso se ve intensificado en la región por la contaminación salina que produce haloclastismo e induce a una mayor destrucción de las rocas.

La hidrólisis sería uno de los mecanismos de la meteorización química que actúa sobre los óxidos de hierro y las arcillas descomponiéndolos en fracciones más simples y, en Puna, este proceso actúa en la estación estival lluviosa. ${ }^{9}$ Las características comunes a los minerales de arcilla derivan de su composición química, estructura laminar, la medida de los cristales y la afinidad que tienen por el agua, por eso, cuando se hidratan, se hinchan y pueden aumentar su espesor hasta casi el doble (Chamley 1989). Cuando se hidroliza un mineral de arcilla, primero pierde los cationes más móviles de los octaedros ( $\mathrm{Na}, \mathrm{K}, \mathrm{Ca}, \mathrm{Mg}$ y $\mathrm{Sr}$ ), luego son removidos los elementos de transición ( $\mathrm{Mn}, \mathrm{Cu}$ y $\mathrm{Fe}$ ) y, por último, los cationes menos móviles ( $\mathrm{Si}$ y $\mathrm{Al}$ ) de los tetraedros y octaedros que pasan en solución al medio (Chamley 1989: 23). A su vez, por hidratación, la hematita -el óxido férrico termodinámicamente más estable, es decir, el menos soluble en un amplio rango de $\mathrm{pH}$ y bajo condiciones oxidantes- puede transformarse en goethita $(\alpha-\mathrm{FeOOH})$, una fase más soluble (Torrent \& Schwertmann 1987; Jang et al. 2007). Bajo condiciones de elevada acidez, la hematita puede hidrolizarse liberando iones $\mathrm{Fe}^{3+}$ al medio (Cornell \& Schwertmann 1996; Jang et al. 2007).

No podemos soslayar en este análisis la diversidad estilística observada entre las representaciones de los tres sitios. A su vez, de la comparación con otros sitios coetáneos, advertimos que el panel de Hor2 (fig. 2) es único en el área y en la región puneña argentina, tanto por las escenas representadas como por la cronología asignada al arte rupestre y al arte mobiliar (talla de

madera fechada en $9590 \pm 50 \mathrm{AP})$. En cuanto a la figura de llama pintada en CQ (fig. 3), este motivo es similar a los de otros sectores de la Puna para el período. Por último, las figuras del panel pintado de TP (fig. 4) evocan parcialmente, por la longitud de los cuerpos, uno de los grupos estilísticos asignado a momentos tempranos -Grupo Estilístico B (GEB)- que ha sido definido por Aschero y colaboradores (1991) para sitios de la Puna argentina. Sin embargo, hay ciertas diferencias estilísticas entre los antropomorfos de TP y los de Inca Cueva -la cintura angosta y la relación cintura/hombros en los antropomorfos de TP y la diferenciación de los miembros inferiores de Inca Cueva- que nos permite sugerir que los grupos humanos responsables de la realización de las pinturas utilizaban espacios geográficos diferentes (figs. 7a y b). Esta separación puede determinarse a partir de accidentes geográficos, como el sistema serrano de rumbo NE-SO (al este de Susques) y la cuenca Laguna de Guayatayoc-Salinas Grandes. Este espacio de separación pudo articular sistemas de movilidad diferente para ambos lugares en relación con los grupos de cazadores recolectores del Holoceno temprano (Yacobaccio et al. 2012). Para momentos posteriores, la cuestión pudo ser

a - Antropomorfos de Tres Pozos
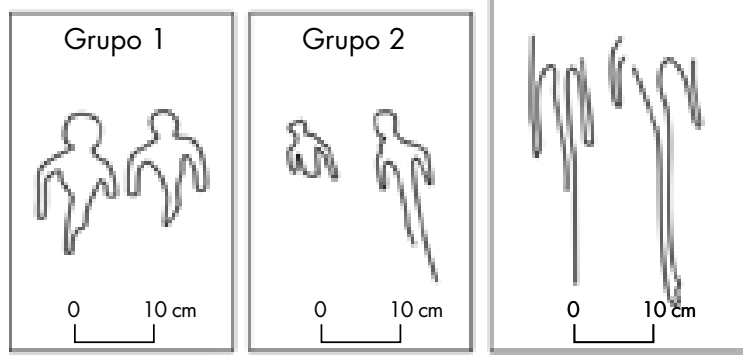

b - Antropomorfos de Inca Cueva

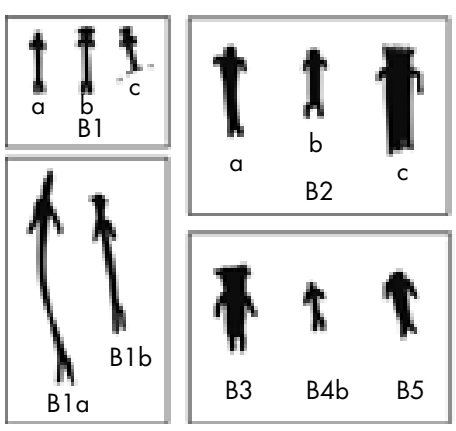

Figura 7. Figuras de antropomorfos pintados en Tres Pozos e Inca Cueva. a) Grupos diferenciados en Tres Pozos. b) Algunos grupos estilísticos (GEB) asignados por Aschero y colaboradores (1991: 36). Figure 7. Anthropomorphic pictures painted at Tres Pozos and Inca Cueva. a) Groups identified at Tres Pozos; b) Some stylistic groups (GEB) defined by Aschero et al. (1991: 36). 
más compleja debido al establecimiento de poblaciones más estables en el ámbito puneño y a la delineación de territorios.

\section{CONCLUSIONES}

Así como la naturaleza de las rocas determina su susceptibilidad a los agentes erosivos, los minerales son más susceptibles a la meteorización química cuanto más débiles son sus uniones químicas y cuanto más lejanas son sus condiciones de formación a las del ambiente superficial. El factor climático se ve reflejado en los minerales y si bien las arcillas se degradan fácilmente en ambientes húmedos, la ocurrencia de hematita es independiente del clima.

La estabilidad cristaloquímica de la hematita aportó durabilidad e intensidad y variabilidad cromática a las pinturas rupestres; sin duda, las arcillas (rojas), mucho más sensibles a la degradación, se adecuaron mejor a otros usos. Prácticamente, no se cuenta en esta región con información etnohistórica que permita inferir esos otros usos. Un caso excepcional en la Puna jujeña oriental es el observado en Inca Cueva (c4) (Holoceno temprano) donde se han registrado distintos tipos de pigmentos rojos en productos de actividades diferentes. En este sitio, las pinturas rojas fueron realizadas con plumbojarosita (en parte, repintadas con hematita) y, aunque en capa, se recuperaron fragmentos de hematita, maghemita y goethita (Aschero 1983-1985), el cuero aludido fue pintado con un material que incluye hematita y minerales arcillosos.

Las fuentes de las materias primas usadas en las pinturas de los tres sitios -Hor2, CQ y TP- han sido diferentes a pesar de que invariablemente el pigmento rojo fue hematita. En trabajos anteriores (Yacobaccio et al. 2008, 2011, 2012) fueron discutidas las cronologías y las relaciones entre las pinturas y las posibles fuentes de pigmentos de Hor2 y CQ. En principio, las fuentes de las materias primas -hematita, anhidrita/yeso y calcitautilizadas en las pinturas de TP podrían correlacionarse con las analizadas en los otros dos sitios (Hor2 y CQ). Las asociaciones minerales determinadas son muy comunes en la Puna de Jujuy y su origen pudo ser local o estar dentro del rango de movilidad establecido para los primeros cazadores-recolectores (Yacobaccio et al. 2008, 2012); las especies minerales establecidas se encuentran en el ámbito de la cuenca de Susques, delimitada al oeste por la Sierra del Taire y al este por la Sierra de los Cobres, incluso en la cuenca vecina (Salinas Grandes), al oriente de la serranía de los Cobres.

Los pigmentos arcillosos debieron ser considerados poco apropiados para plasmar las figuras porque no fueron empleados a pesar de la existencia de extensos y potentes mantos arcillosos rojizos (10R 5/4 Weak red) compuestos principalmente por esmectitas en asociación con illita, muscovita y clorita. ${ }^{10}$

Los estudios tecnológicos abordados proveen información sobre el comportamiento y las elecciones de los artesanos quienes debieron "guiarse" por el color, las propiedades específicas de los recursos utilizados y el conocimiento adquirido acerca de su manipulación. Es decir, las elecciones sobre la conveniencia de aplicar alguno de los dos tipos de pigmentos dependían de las performances de las materias primas: óxidos férricos versus arcillas (rojas). Las diferencias entre ambas especies minerales son sustanciales; mientras que los óxidos son mucho más resistentes al intemperismo y a la degradación lumínica, las arcillas son plásticas y dúctiles y están suficientemente coloreadas para ser utilizadas como materiales pigmentantes en actividades diferentes, efímeras o no, como serían la pintura facial y la producción cerámica.

El potencial de la hematita como pigmento rojo quedó evidenciado en las pictografías locales desde el Pleistoceno / Holoceno temprano. Diferente ha sido el caso de las arcillas (rojas) cuyo potencial como material pigmentante es bien conocido, pero, en los sitios precerámicos del área, su uso no ha sido totalmente dilucidado. La composición de la pintura conservada en el cuero de Inca Cueva (c4) no fue suficientemente concluyente para poder consolidar nuestra hipótesis inicial sobre el uso específico de arcillas (rojas), por ejemplo, en pintura de cueros. No debemos olvidar, sin embargo, que hay registros etnográficos de aplicación de ocre como parte del curtido de los cueros, ya que puede tener propiedades bactericidas que contribuyen a su preparación con el fin de ser empleados en la confección de diferentes artefactos (Audoin \& Plisson 1982; Wadley 2005). En una publicación anterior se reconoció la importancia del trabajo de preparación de cueros durante la ocupación de la capa 2 de Inca Cueva (c4) que incluyó el empleo de diferentes aditivos (grasa) y secantes (ceniza y ocre) (Yacobaccio 1986). Ya en tiempos posteriores, y con la introducción de la alfarería, las arcillas experimentaron nuevas y variadas aplicaciones y los óxidos de hierro continuaron siendo los pigmentos rojos por excelencia de las pinturas rupestres de este sector de la Puna jujeña.

RECONOCIMIENTOS A los departamentos de Geología y de Química Orgánica de la Facultad de Ciencias Exactas y Naturales (UBA), a la Gerencia Química de la Comisión Nacional de Energía Atómica (Centro Atómico Constituyentes), al Laboratorio Nacional de Luz Sincrotrón (Campinas, Brasil), al Laboratorio de Difractometría de Rayos X del SEGEMAR (INTI) y al Centro de Microscopias Avanzadas de la Facultad de Ciencias Exactas y Naturales (UBA). A los tres evaluadores por sus atinados comentarios y sugerencias. Esta investigación fue solventada con subsidios PIP 3173 (CONICET) y UBACYT F152 (Universidad de Buenos Aires). 


\section{NOTAS}

1 La cerámica es fragmentaria. Las paredes son lisas y los colores comprenden varias gamas de castaño; algunos tiestos provienen de vasijas con tratamiento interior negro.

2 Cromógeno (del gr., chroma: color y genno: que genera): compuesto que contiene al elemento cromóforo en la estructura cristalina, ya sea como elemento fundamental $\left[\mathrm{Fe}^{3+}\right.$ en hematita] o como traza en la estructura mineral. Cromóforo (chroma: color y phor(o): que lleva): elemento químico que reacciona frente a la luz produciendo un delta de energía, el electrón produce la emisión del color cuando salta a otro nivel energético.

3 Los iones de algunos elementos tienen la propiedad de absorber selectivamente diferentes longitudes de onda $(\lambda)$ de luz. Estos elementos son cromóforos, poseen fuerte capacidad pigmentante y pueden producir color aun estando en proporciones traza. El color se origina cuando la luz incide sobre un mineral donde algunas longitudes de onda de la luz visible son absorbidas por los átomos de la red cristalina mientras que otras son reflejadas por la superficie del mineral y llegan al observador (el color percibido depende de las longitudes de onda de luz reflejadas más que de aquellas absorbidas por el mineral). Los elementos (metales) de transición, p. e., manganeso (Mn), hierro $(\mathrm{Fe})$, cobre $(\mathrm{Cu})$ son cromóforos y son los responsables del color de los minerales. La presencia de uno o más de estos cromóforos puede conferir un color vívido y distintivo al mineral; el color y su intensidad son proporcionales a la cantidad de cromóforo presente en el cristal. A su vez, los minerales que contienen cromóforos en la estructura cristalina son cromógenos y generan color (Wenk \& Bulakh 2004).

${ }^{4}$ Los oxihidróxidos de hierro, ocasionalmente, están formados por un tetraedro con el catión férrico rodeado por oxígenos u oxidrilos, con fuertes uniones covalentes ( $\mathrm{Fe}-\mathrm{O})$ que originan un empaquetamiento casi hexagonal, levemente distorsionado (Cornell \& Schwertmann 1996; Cudennec \& Lecerf 2006).

5 En la estructura cristalina de los filosilicatos intervienen diferentes tipos de uniones químicas entre las hojas y entre las láminas: a) uniones catión-anión (intermedias entre uniones iónicas y covalentes) entre los átomos que forman las hojas de tetraedros y octaedros (Meunier 2005) y b) uniones intermoleculares de intercapa por la acción de fuerzas de Van der Waals (enlaces muy débiles) que promueven el espacio interlaminar y las uniones puente de hidrógeno (débiles) entre los cationes hidratados de intercapa y las capas tetraédricas.

${ }^{6}$ Instrumental: difractómetro Philips 1130 (radiación de Co filtrada con $\mathrm{Fe}$, a $2^{\circ} 2 \mathrm{Q} / \mathrm{min}$; rango de sensibilidad: $2^{*} 10[3]$ ); difractómetro Siemens D5000 (radiación $\mathrm{Cu} / \mathrm{Ni}$ ); espectrómetro de rayos $\mathrm{X}$ por dispersión de energía (EDS) Falcon PV 8200 acoplado a un microscopio electrónico de barrido (MEB) Philips 515; microscopio electrónico de barrido Zeiss modelo Supra 40 adosado a un cañón de electrones por emisión de campo (EDS) marca Oxford Instruments modelo Inca x-Sight; espectrómetro Nicolet Magna 550 (FT-IR) y cromatógrafo de gases (CG) Hewlett-Packard 5890A acoplado a un espectrómetro de masa (EM) TRIO-2 VG. Los valores obtenidos mediante DRX y CG son cualitativos y los resultados de EDS son semicuantitativos.

7 Los pigmentos arcillosos de capa de Hor2 y CQ contienen vestigios de hematita (no se ha establecido si está contenida en la estructura de la arcilla o si es una fase separada). Según Muller y Calas (1993, en Malengreau et al. 1994), difícilmente pueda detectarse mediante DRX el óxido de hierro libre contenido en las arcillas.

${ }^{8}$ La abundancia de yeso y anhidrita detectada en las pinturas produjo un efecto dilución sobre el hierro contenido en los pigmentos utilizados para producir dichas pinturas.

9 La hidrólisis es el proceso químico por el cual una molécula determinada se separa en dos partes por la adición de una molécula de agua. Una parte de la molécula original gana iones hidrógeno $\left(\mathrm{H}^{+}\right)$desde la molécula de agua y la otra parte retiene los oxidrilos $\left(\mathrm{OH}^{-}\right)$. El proceso puede originar nuevos minerales.
10 Las arcillas expandibles son poco adecuadas para pintar sobre pared porque la interacción arcilla-agua dañaría las pinturas debido al cambio de volumen (Cornell \& Schwertmann 1996: 230).

\section{REFERENCIAS}

Aguerre, A. M.; A. A. Fernández Distel \& C. A. Aschero, 1973. Hallazgo de un sitio acerámico en la Quebrada de Inca Cueva (Prov. de Jujuy). Relaciones de la Sociedad Argentina de Antropología (N. S.) VII: 197-235.

Aguerre, A. M., 2000. Las vidas de Pati en la toldería Tehuelche del Río Pinturas y el después. Buenos Aires: Universidad de Buenos Aires, Facultad de Filosofía y Letras.

Alonso, R. N., 2006. Ambientes evaporíticos continentales de Argentina. Temas de la Geología Argentina I (2) INSUGEO, Serie Correlación Geológica 21: 155-170.

Aschero, C., 1983-1985. Pinturas rupestres en asentamientos cazadores recolectores: Dos casos de análisis aplicando difracción de rayos X. Cuadernos del Instituto Nacional de Antropología 10: 291-306

— 1984. El sitio ICC-4: Un asentamiento precerámico en la quebrada de Inca Cueva (Jujuy, Argentina). Estudios Atacameños 7: 53-60.

Aschero, C. \& M. M. PoDEstÁ, 1986. El arte rupestre en asentamientos precerámicos de la Puna argentina. Runa XVI: 29-57.

Aschero, C.; M. M. Podestá \& L. García, 1991. Pinturas rupestres y asentamientos cerámicos tempranos en la Puna argentina. Arqueología 1: 9-50.

Audouin, F. \& H. Plisson, 1982. Les ocres et leurs témoins au Paléolithique en France; enquête et expériences sur leur validité archéologique. Cabiers du Centre de Recherches Prébistoriques de Paris I (8): 33-80.

BALLIVIAN, O. \& F. RISACHER, 1981. Los salares del altiplano boliviano. Métodos de estudio y estimación económica. París: ORSTOM.

Barbosa, C. \& C. J. Gradin, 1986-1987. Estudio composicional por difracción de rayos $\mathrm{X}$ de los pigmentos provenientes de la excavación del Alero Cárdenas (Prov. de Santa Cruz). Relaciones de la Sociedad Argentina de Antropología XVII (1): 143-171.

Boschin, M. T.; M. S. Maier \& G. I. Massaferro, 2011. Une lecture pluridisciplinaire des analyses chimiques et minéralogiques de peintures rupestres de la Patagonie argentine. L'anthropologie 115: 360-383.

Boschin, M. T.; A. Seldes, M. Maier, R. Casamiquela, R. Ledesma \& G. ABAD, 2002. Análisis de las fracciones inorgánica y orgánica de pinturas rupestres y pastas de sitios arqueológicos de la Patagonia septentrional argentina. Zephyrus 55: 183-198.

Casanova, E., 1967. Una significativa pictografía de la Puna jujeña. Antiquitas V: 1-3.

Caviglia, S. E., 2003 (2002). El arte de las mujeres aónik'enk y gününa küna -kay uaj'enk o kay gütrruj (las capas pintadas). Relaciones de la Sociedad Argentina de Antropología XXVII: 41-77.

Chamley, H., 1989. Clay Sedimentology. Berlin: Springer-Verlag.

Cornell, R. M. \& U. Schwertmann, 1996. The Iron Oxides. Structure, Properties, Reactions, Occurrence and Uses. Weinheim: VCH.

Cudennec, Y. \& A. LeCERF, 2006. The transformation of ferrihydrite into goethite or hematite, revisited. Journal of Solid State Chemistry 179: 716-722.

Dana, E. S. \& W. E. Ford, 1973. Tratado de mineralogía. México, D. F.: Compañía Editorial Continental.

FernánDEZ, J., 1976. Arqueología de la Cueva de El Toro (Departamento Susques, Jujuy). Relaciones de la Sociedad Argentina de Antropología X: 43-65.

- 1988-1989. Ocupaciones alfareras (2860 \pm 160 años AP) en la cueva de Cristóbal, Puna de Jujuy, Argentina. Relaciones de la Sociedad Argentina de Antropología (N. S.) XVII (2): 139-182.

FERnÁndez Distel, A., 2001. Catálogo del arte rupestre: Jujuy y su Región. Buenos Aires: Editorial Dunken. 
Fiore, D., 2004. Pieles rojas en el confín del mundo. La valoración de las pinturas corporales en los registros histórico-etnográficos sobre aborígenes de Tierra del Fuego. Magallania 32: 29-52.

— 2006. La manipulación de pinturas corporales como factor de división social en los pueblos selk'nam y yámana (Tierra del Fuego). Estudios Atacameños 31: 129-142.

Fiore, D.; M. Maier, S. D. Parera, L. Orquera \& E. Piana, 2008 Chemical analyses of the earliest pigment residues from the uttermost part of the planet (Beagle Channel region, Tierra del Fuego, Southern South America). Journal of Archaeological Science 35: 3047-3056.

Gómez Otero, J., 1996-1997. Rescate y reinserción de los Mantos de Pieles (Quillangos) Indígenas de Patagonia en la Provincia del Chubut (Argentina). Cuadernos del Instituto Nacional de Antropología y Pensamiento Latinoamericano 17: 69-87.

GonzÁlez de Bonaveri, M. I.; M. M. Frère \& P. Solá, 2000. Petrografía de cerámicas arqueológicas de la cuenca del río Salado, Provincia de Buenos Aires. Relaciones de la Sociedad Argentina de Antropología XXV: 207-226.

Gradin, C. J., 1978. Pinturas rupestres del Alero Cárdenas (Prov. de Santa Cruz). Relaciones de la Sociedad Argentina de Antropología XI: 143-158.

HajDuk, A., 1978. Excepcionales ceramios de la Provincia del Neuquén. Presencia de alfarería con decoración por pintura resistente, en la Provincia del Neuquén (Argentina). Algunas consideraciones en torno a ella. Revista del Museo Provincial I (1): 103-119, Neuquén.

Hernández Llosas, M. I. \& M. M. Podestá, 1979-1982. Las pinturas rupestres del alero de las Circunferencias (Depto. Humahuaca, Prov. de Jujuy). Cuadernos del Instituto Nacional de Antropología 9: 37-58, Buenos Aires.

— 1983-1985. Las pinturas rupestres del Abrigo de los Emplumados. Cuadernos del Instituto Nacional de Antropología 10: 387-406, Buenos Aires.

Hernández Llosas, M. I.; A. Watchman \& J. Southon, 1999. Pigment analysis and absolute dating of rock paintings from Jujuy, Argentina. En Dating and the earliest known rock art, M. Strecker \& P. Bahn, Eds., pp. 67-74. Oxford: Oxbow Books.

Hoguin, R.; M. P. Catá, P. Solá \& H. D. Yacobaccio, 2012. The spatial organization in Hornillos 2 rockshelter during the Middle Holocene (Jujuy Puna, Argentina). Quaternary International 256 (4): 45-53.

Hradil, D.; T. Grygar, J. Hradilova \& P. Bezdicka, 2003. Clay and iron oxide pigments in the history of painting. Applied Clay Science 22 (5): 223-236.

IÑígueZ, A. M. \& C. J. Gradin, 1977. Análisis mineral por difracción de rayos $\mathrm{X}$ de muestras de pinturas de la Cueva de las Manos, Estancia Alto Río Pinturas (Provincia de Santa Cruz). Relaciones de la Sociedad Argentina de Antropología (N. S.) XI: 121-128

Jang, J. H.; B. A. Dempsey \& W. D. Burgos, 2007. Solubility of Hematite Revisited: Effects of Hydration. Environmental Sciemce E Technology 41 (21): 7303-7308.

KonTA, J., 1995. Clay and man: Clay raw materials in the service of man. Applied Clay Science 10: 275-335.

Lagiglia, H., 1997. Arqueología prehistórica del Atuel y Diamante. Revista del Centro de Investigación Territorial (CINTER) 2: 29-46.

Lambe, T. W. \& R. V. Whitman, 1969. Mecánica de suelos. México, D. F.: Ed. Limusa.

LÓpez, P. L.; L. F. Auqué, I. Garcés \& G. ChOnG, 1999. Características geoquímicas y pautas de evolución de las salmueras superficiales del salar de Llamara, Chile. Revista Geológica de Chile 26 (1): 89-108.

Maier, M. S.; D. L. A. De Faria, M. T. Boschin, S. D. Parera \& M. F. Dei CASTILlo BERNAL, 2007. Combined use of vibrational spectroscopy and GC-MS methods in the characterization of archaeological pastes from Patagonia. Vibrational Spectroscopy 44: 182-186.

Malengreau, N.; J. P. Muller \& G. Calas, 1994. Fe-speciation in kaolins: a diffuse reflectance study. Clays and Clay Minerals 42 (2): 137-147.
Martínez, G.; P. Bayala, G. Flensborg \& R. López, 2006. Análisis preliminar de los entierros humanos del sitio Paso Alsina 1 (Prov. de Buenos Aires). Intersecciones en Antropología 7: 95-108.

Matarrese, A.; V. Di Prado \& D. G. Poiré, 2011. Petrologic analysis of mineral pigments from hunter-gatherers archaeological contexts (Southeastern Pampean region, Argentina). Quaternary International 245: 2-12.

Meunier, A., 2005. Clays. Berlin: Springer-Verlag Berlin Heidelberg.

Murray, H.H., 2007. Applied Clay Mineralogy Occurrences, Processing and Application of Kaolins Bentonites Palygorskite-Sepiolite and Common Clays. Elsevier Developments in Clay Science 2, Oxford.

Ovejero Toledo, A.; R. N. Alonso, T. Del V. Ruiz \& A. G. Quiroga, 2009. Evapofacies halítica en el salar del Rincón, Departamento los Andes, Salta. Revista de la Asociación Geológica Argentina 64 (3): 493-500.

Paunero, R. S.; A. Frank, F. Skarbun, G. Rosales, G. Zapata, M. Cueto, M. F. Paunero, D. G. Martínez, R. López, N. Lunazzi \& M. Del Giorgio, 2005. Arte rupestre en la Estancia La María, Meseta Central de Santa Cruz: Sectorización y contextos arqueológicos. Relaciones de la Sociedad Argentina de Antropología XXX: 147-168

Pérez, M., 2009. Tecnología de producción de la alfarería durante el Holoceno tardío en el humedal del Paraná inferior. Un estudio petrográfico. Tesis de Licenciatura para optar por el título de Licenciado en Ciencias Antropológicas, orientación Arqueología. Facultad de Filosofía y Letras, Universidad de Buenos Aires.

Rosen, E. vON, 1957. Un mundo que se va. Exploraciones y aventuras entre las altas cumbres de la cordillera de los Andes. Tucumán: Fundación Miguel Lillo, Universidad Nacional de Tucumán e Instituto Miguel Lillo.

Schobinger J. \& C. Gradin, 1985. Cazadores en Patagonia y agricultores andinos, arte rupestre de la Argentina. Madrid: Editorial Encuentro.

Torrent, J. \& U. Schwertmann, 1987. Influence of hematite on the color of red beds. Journal of Sedimentary Petrology 57: 682-686.

Vázquez, C.; M. S. Maier, S. D. Parera, H. D. Yacobaccio \& P. Solá, 2008. Combining TXRF, FT-IR and GC-MS information for the identification of inorganic and organic components in black pigments of rock art from Alero Hornillos 2 (Jujuy, Argentina). Analytical \& Bioanalytical Chemistry (ABC), Special Issue: Euroanalysis, 391 (4): 1381-1387.

WADLEY, L., 2005. Putting ochre to the test: replication studies of adhesives that may have been used for hafting tools in the Middle Stone Age. Journal of Human Evolution 49: 587-601.

Wainwright, I. K.; M. K. Helwig, M. M. Podestá \& C. Bellelli, 2000. Analysis of pigments from rock painting sites in Río Negro and Chubut provinces. En Arte en las rocas. Arte rupestre, menbires y piedras de colores en Argentina, M. M. Podestá \& M. de Hoyos, Eds., pp. 203-206. Buenos Aires: Sociedad Argentina de Antropología, Asociación Amigos del Instituto Nacional de Antropología y Pensamiento Latinoamericano.

Wainwright, I. K.; M. K. Helwig, D. S. Rolandi, C. Gradin, M. M. Podestá, M. Onetto \& C. A. Aschero, 2002. Rock paintings conservation and pigment analysis at Cueva de las Manos and Cerro de los Indios, Santa Cruz (Patagonia), Argentina. En 13th Triennial Meeting Río de Janeiro Preprints Vol II, pp. 582-589. London: James.

Wenk, H. R. \& A. G. BulakH, 2004. Minerals: Their Constitution and Origin. Oxford: Cambridge University Press.

Yacobaccio, H. D., 1986. Análisis de artefactos con substancias adheridas de Inca Cueva-4. Revista Antropológica II (4): 15-22, Montevideo.

Yacobaccio, H. D.; M. P. Catá, M. R. Morales, P. Solá, M. S. Alonso, M. Rosenbusch, C. Vázquez, C. Samec, B. Oxman \& M. Cáceres, 2011. El uso de cuevas por pastores andinos: El caso de Cueva Quispe (Susques, Puna de Jujuy). En Arqueología de la Puna argentina: Perspectivas actuales en el estudio de la diversidad y el cambio cultural, H. Muscio \& G. López, Eds., pp. 33-48. Oxford: Archaeopress. 
Yacobaccio, H. D.; M. P. Catá, P. Solá \& M. S. Alonso, 2008. Estudio arqueológico y fisicoquímico de pinturas rupestres en Hornillos 2 (Puna jujeña, Argentina). Estudios Atacameños 36: 5-28.

Yacobaccio, H. D.; C. M. Madero, M. P. Malmierca \& M. C. Reigadas, 1997-1998. Caza, domesticación y pastoreo de camélidos en la Puna argentina. Relaciones de la Sociedad Argentina de Antropología XXII-XXIII: 389-418.

Yacobaccio, H. D.; M. R. Morales, P. Solá, C. T. Samec, R. Hoguin \& B. I. Oxman, 2013. Mid- Holocene occupation of the Dry Puna in NW Argentina: Evidence from the Hornillos 2 rockshelter. Quaternary International 307: 38-49.
Yacobaccio, H. D.; P. Solá, M. S. Alonso, M. S. Maier, M. Rosenbusch, C. VÁzQuez \& M. P. CATÁ, 2012. Pinturas Rupestres del Pleistoceno / Holoceno en la Puna de Atacama (Jujuy, Argentina). En L'art pléistocène dans le monde / Pleistocene art of the world / Arte pleistoceno en el Mundo, Actes du Congrès IFRAO, Tarasconsur-Ariège, septembre 2010, Symposium "Art pléistocène dans les Amériques". No Spécial de Prébistoire, Art et Sociétés, Bulletin de la Société Prébistorique Ariège-Pyrénées, LXV-LXVI, 2010-2011, CD: 751-772. 
